Article

\title{
BRCA1 Promoter Hypermethylation is Associated with Good Prognosis and Chemosensitivity in Triple-Negative Breast Cancer
}

\author{
William Jacot ${ }^{1,2,3,4, *}$, Evelyne Lopez-Crapez ${ }^{2,4}$, Caroline Mollevi ${ }^{4,5}$, Florence Boissière-Michot ${ }^{2}$, \\ Joelle Simony-Lafontaine ${ }^{2}$, Alexandre Ho-Pun-Cheung ${ }^{2}$, Elodie Chartron ${ }^{1}$, Charles Theillet ${ }^{4}$, \\ Antoinette Lemoine ${ }^{6}$, Raphael Saffroy ${ }^{6}$, Pierre-Jean Lamy ${ }^{7,8}{ }^{[1}$ and Séverine Guiu ${ }^{1,4}$ \\ 1 Department of Medical Oncology, Montpellier Cancer Institute Val d'Aurelle, 208 rue des Apothicaires, \\ F-34298 Montpellier, France; Elodie.Chartron@icm.unicancer.fr (E.C.); severine.guiu@icm.unicancer.fr (S.G.) \\ 2 Translational Research Unit, Montpellier Cancer Institute Val d'Aurelle, 208 rue des Apothicaires, \\ F-34298 Montpellier, France; Evelyne.Crapez@icm.unicancer.fr (E.L.-C.); \\ Florence.Boissiere@icm.unicancer.fr (F.B.-M.); Joelle.Simony@icm.unicancer.fr (J.S.-L.); \\ Alexandre.Ho-pun-cheung@icm.unicancer.fr (A.H.-P.-C.) \\ 3 Faculty of Medicine, Montpellier University, 34090 Montpellier, France \\ 4 Institut de Recherche en Cancérologie de Montpellier (IRCM), Inserm U1194, Université de Montpellier, \\ Institut du Cancer Montpellier (ICM), F-34298 Montpellier, France; caroline.mollevi@icm.unicancer.fr (C.M.); \\ charles.theillet@inserm.fr (C.T.) \\ 5 Biometrics Unit, Institut du Cancer Montpellier (ICM), Université de Montpellier, 208 rue des Apothicaires, \\ F-34298 Montpellier, France \\ 6 Department of Oncogenetics, APHP, GH Paris-Sud, Hôpital Paul Brousse, Inserm UMR-S 1193, \\ Université Paris-Saclay, 14 Avenue Paul Vaillant Couturier, 94800 Villejuif, France; \\ antoinette.lemoine@aphp.fr (A.L.); raphael.saffroy@aphp.fr (R.S.) \\ 7 Institut d'Analyse Génomique, Imagenome-Inovie, Clinique BeauSoleil, 34070 Montpellier, France; \\ pierre-jean.lamy@labosud.fr \\ 8 Biological Resources Center, Montpellier Cancer Institute Val d'Aurelle, F-34298 Montpellier, France \\ * Correspondence: william.jacot@icm.unicancer.fr; Tel.: +33-4-67-61-31-00; Fax: +33-4-67-63-28-73
}

Received: 2 March 2020; Accepted: 26 March 2020; Published: 30 March 2020

check for updates

\begin{abstract}
The aberrant hypermethylation of $B R C A 1$ promoter $\mathrm{CpG}$ islands induces the decreased expression of BRCA1 (Breast Cancer 1) protein. It can be detected in sporadic breast cancer without $B R C A 1$ pathogenic variants, particularly in triple-negative breast cancers (TNBC). We investigated $B R C A 1$ hypermethylation status (by methylation-specific polymerase chain reaction (MS-PCR) and MassARRAY ${ }^{\circledR}$ assays), and BRCA1 protein expression using immunohistochemistry (IHC), and their clinicopathological significance in 248 chemotherapy-naïve TNBC samples. Fifty-five tumors (22\%) exhibited BRCA1 promoter hypermethylation, with a high concordance rate between MS-PCR and MassARRAY ${ }^{\circledR}$ results. Promoter hypermethylation was associated with reduced IHC BRCA1 protein expression ( $p=0.005)$, and expression of Programmed death-ligand 1 protein (PD-L1) by tumor and immune cells ( $p=0.03$ and 0.011 , respectively). A trend was found between promoter hypermethylation and basal marker staining $(p=0.058)$, and between BRCA1 expression and a basal-like phenotype. In multivariate analysis, relapse-free survival was significantly associated with N stage, adjuvant chemotherapy, and histological subtype. Overall survival was significantly associated with $\mathrm{T}$ and $\mathrm{N}$ stage, histology, and adjuvant chemotherapy. In addition, patients with tumors harboring $B R C A 1$ promoter hypermethylation derived the most benefit from adjuvant chemotherapy. In conclusion, $B R C A 1$ promoter hypermethylation is associated with TNBC sensitivity to adjuvant chemotherapy, basal-like features and PD-L1 expression. BRCA1 IHC expression is not a good surrogate marker for promoter hypermethylation and is not independently associated with prognosis. Association between promoter hypermethylation and sensitivity to Poly(ADP-ribose) polymerase PARP inhibitors needs to be evaluated in a specific series of patients.
\end{abstract}


Keywords: triple-negative breast cancer; BRCA1; expression; promoter hypermethylation; prognosis; basal-like

\section{Introduction}

Triple-negative breast cancers (TNBCs) represent $15 \%$ of all breast cancers (BCs) and are defined by the absence of estrogen receptors (ERs), progesterone receptors (PRs), and Growth Factor Receptor-2 (HER2) overexpression/amplification [1,2]. Despite the good chemosensitivity of these tumors, patients with TNBC have a poor prognosis [1,3]. Based on hierarchical clustering, Perou et al. initially described five 'intrinsic' molecular BC subtypes, including a basal-like subtype [4,5]. Approximately $70 \%$ of basal-like BCs have a triple-negative phenotype (defined by immunohistochemistry [IHC]) and, using the PAM50 classifier, $80 \%$ of TNBCs can be classified as basal-like tumors [6]. An expanded surrogate immunopanel of markers (ER, PR, HER2, EGFR, and cytokeratin [CK] 5/6) provides a more specific IHC definition of basal-like BC [7]. Overall, $70 \%$ to $80 \%$ of BCs due to hereditary BRCA1 pathogenic variants are TNBC [8-10]. 'BRCAness' is defined by the phenotypic similarities that some sporadic cancers share with those occurring in either BRCA1- or BRCA2-mutation carriers [11]. These tumors share a common deficiency in DNA repair.

Upregulation of their DNA repair capacity is a common mechanism used by cancer cells to survive DNA-damaging therapy [12]. Lack of efficient DNA repair by the simultaneous loss or inhibition of two DNA repair pathways causes synthetic lethality and cell death, thus representing an attractive approach for cancer therapy [13], emphasized by the clinical activity of poly(ADP-ribose) (PAR) polymerase 1 (PARP) inhibitors (PARPi) in patients with BRCA-mutated BC [14-16].

Identifying BRCA-deficient tumors is therefore of tremendous importance in this setting. The absence of BRCA1 nuclear expression correlates with high tumor grade and ER-negative tumors [17]. Absent or reduced BRCA1 expression in tumors without BRCA1 pathogenic variants appears to be linked to hypermethylation of the BRCA1 promoter region [18], a condition reported in $9.1-37 \%$ of sporadic BCs and associated with infiltrating ductal carcinoma type, high tumor grade (grade II-III), ER negativity, basal marker expression, younger age at diagnosis, and poor prognosis [18-29]. Thus, BRCA1 promoter hypermethylation could be a marker of BRCA1 deficiency in the absence of BRCA1 mutation, as these two events appear to be almost mutually exclusive [23,30-34], outside of the recently described association between a dominantly inherited 5' UTR variant, classified as likely pathogenic, and $B R C A 1$ promoter hypermethylation [35]. In contrast, no BRCA2 promoter methylation is implicated in breast carcinogenesis and rarely so in ovarian cancer [36]. Instead, BRCA2 expression has been proposed to be down-regulated by EMSY, a chromatin remodeling protein, shown to interact with the BRCA2 transactivation domain and to repress its transcription. The EMSY gene is amplified and overexpressed in 13\% BC and 17\% HGSOC and this is considered as a manifestation of BRCA2 inactivation in these tumors [37].

Outside of $B R C A 1 / 2$ pathogenic variants, there is to date no validated screening test to identify breast cancer patients who may derive the most benefit from PARPi. Recent data show that most non-BRCA-mutated TNBCs do not benefit from such drugs, while some non-TN BRCA-mutated tumors do respond to PARPi [38]. Moreover, two different groups [39,40] reported that BCs with epigenetically silenced $B R C A 1$ are sensitive to PARP $i$ monotherapy, providing initial evidence to support the use of PARP $i$ to treat selected sporadic BRCA1-inactivated BCs. BRCA1 promoter hypermethylation is therefore a biomarker of interest in TNBC. In order to find a simple and reproducible test, previous studies evaluated whether BRCA1 protein expression assessed using IHC could act as a surrogate marker for $B R C A 1$ transcription. The correlation between levels of $B R C A 1$ transcription and Western blot protein quantification has been reported as weak [41]. In the study by Al-Mula et al., the same weak correlation was found between IHC protein evaluation and mRNA levels quantification, using real-time RT-PCR [42]. Reported correlations with epigenetic inactivation 
through promoter hypermethylation varied, from good correlations in high-grade ovarian serous carcinoma [43] to weak in BC [44]. BRCA1 IHC evaluation suffers from considerable run-to-run variability [41]. Recent conflicting data on the association between patient prognosis and BRCA1 IHC status or $B R C A 1$ promoter hypermethylation levels $[27,43,45]$ mean a comprehensive evaluation of both as potential TNBC biomarkers is required. Identification of additional targets, such as immune checkpoint proteins, would allow better refinement of the definition and therapeutic targeting [46] of this tumor population. Indeed, an association has been described between genomic instability and sensitivity to immune checkpoint-targeted therapies [47]. Thus, PD-L1 expression in the context of BRCA1-deficient tumors could indicate a putative candidate population for PD-L1 inhibition [48].

Here, we simultaneously evaluated BRCA1 methylation status and BRCA1 protein expression and their clinicopathological significance in a population of 248 sporadic TNBCs from patients without familial $\mathrm{BC}$ history or known germline $B R C A 1$ pathogenic variants, in order to evaluate the robustness of the IHC evaluation of protein expression as a surrogate endpoint of epigenetic inactivation, and to evaluate their association with prognosis and PD-L1 expression.

\section{Results}

\subsection{Patient and Tumor Characteristics}

Only cases with available BRCA1 IHC analysis and BRCA1 promoter methylation status were selected for this study $(n=248$; Figure 1$)$.

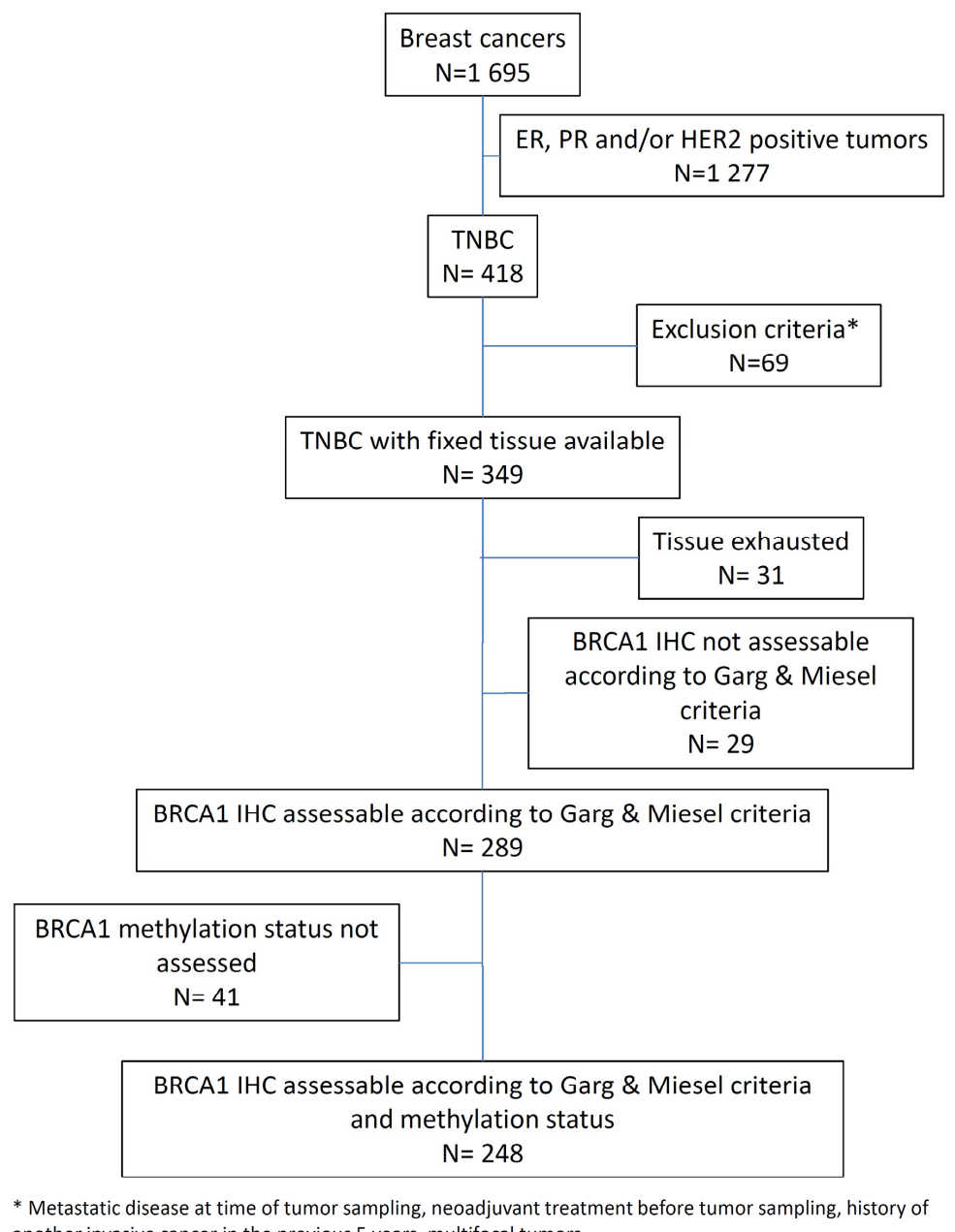
another invasive cancer in the previous 5 years, multifocal tumors

Figure 1. Consort diagram. 
Table 1 summarizes the main clinicopathological characteristics of this cohort, which were consistent with classical TNBC features. The patients' median age was 57.8 years (range: 28.5-98.6 years). Ductal carcinoma was the most common histological type (82.9\%), and $73.3 \%$ of patients received adjuvant chemotherapy (CT), while the remaining $26.7 \%$ of patients received adjuvant radiation therapy only, if clinically indicated. As per our guidelines, our patients received either anthracycline-based chemotherapy (four to six cycles of FEC100/EC 100/FAC65, 33.1\% of the patients) or sequential anthracyclines and taxanes-based chemotherapy (three cycles of FEC100/EC100, followed by three cycles of three-weekly docetaxel or nine injections of weekly paclitaxel, $62.4 \%$ of the patients). Five patients received taxane-based chemotherapy, and one patient received three cycles of CMF followed by three cycles of taxanes, due to a previous history of anthracyclines treatment for a hematologic malignancy. Only one of our patients received an adjuvant platinum salts-based chemotherapy (six cycles of docetaxel—carboplatin, due to cardiovascular comorbidities precluding the use of anthracyclines). None of the patients received additional hormonal therapy, targeted therapy, or an investigational product.

\subsection{In Situ BRCA1 IHC Analysis}

In this study, we used the previously validated MS110 monoclonal antibody [43,49] to detect the expression of BRCA1 by IHC in a cohort of 349 TNBCs arrayed on six tissue microarrays (TMAs). The IHC procedure was previously optimized on full-face tissue sections, using various conditions of antigen retrieval, antibody dilution, amplification steps, and signal detection. All TMA sections were stained in the same run with the optimized procedure. Due to the heterogeneity of BRCA1 expression, samples scored as absent or equivocal were assessed subsequently on full-face sections. BRCA1 expression was considered uninterpretable for 31 cases, in which the tissue cores were lost during processing or showed nonspecific IHC staining. Twenty-nine of the 318 remaining cases (9.1\%) were unclassifiable following Garg and Meisel criteria (for example, weak or moderate staining of $10 \%$ of tumor cell nuclei in the presence of a weak internal positive control). Of the remaining 289 cases, tumor DNA was not available for 41 cases. Overall, 248 cases were assessed for both BRCA1 protein expression and BRCA1 promoter hypermethylation and constituted the analyzed data set (Figure 2). Following Garg and Meisel criteria, of 248 cases, 165 (66.5\%), 70 (28.2\%), and 13 (5.2\%) displayed retained, absent, and equivocal BRCA1 staining, respectively (Figure S1).

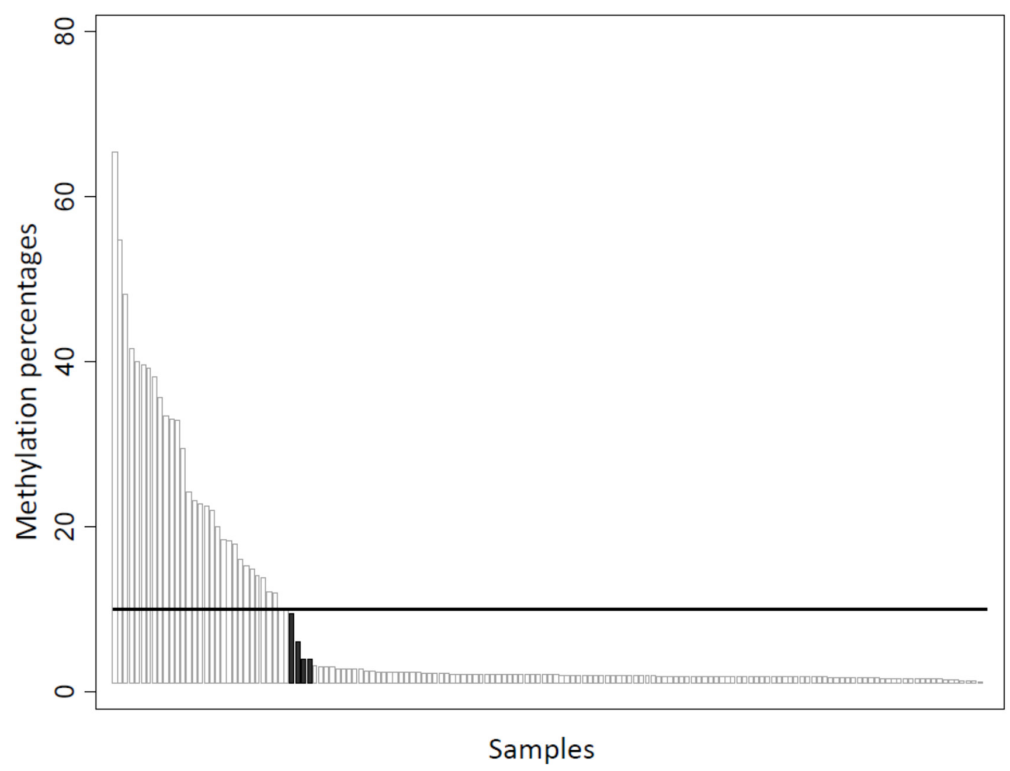

Figure 2. Correlation between methylation-specific PCR and EpiTYPER®MassARRAY®methylation evaluation $(n=153)$. Black columns indicate discordant cases $(n=4$, methylation percentage assessed by MassARRAY $(=9.5,6,4$, and 4$)$, using a positivity cut-off of $10 \%$. 
Table 1. Patients and tumors characteristics.

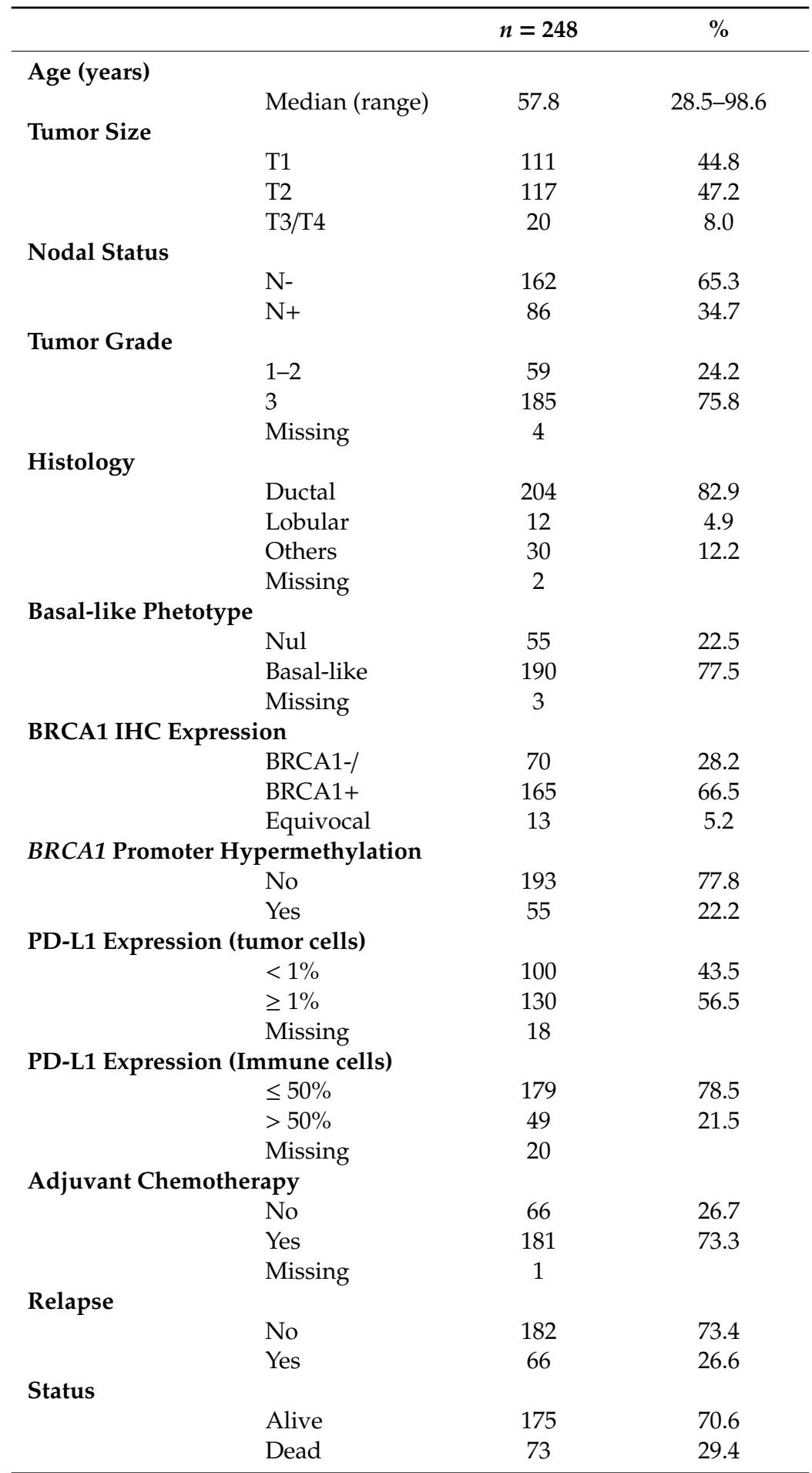

BRCA1: Breast Cancer 1; EGFR: Epithelial Growth Factor Receptor. Basal-like phenotype was considered in case of a positive staining for either cytokeratins $5 / 6$ and/or EGFR $(\geq 1 \%$ tumor cells stained in IHC), while nul phenotype was considered in the absence of cytokeratins 5/6 and EGFR staining.

\subsection{Detection of BRCA1 Promoter Hypermethylation}

$B R C A 1$ promoter hypermethylation status was evaluated by MS-PCR assays on the entire cohort. In addition, MassARRAY ${ }^{\circledR}$ platform testing was carried out on 153 tumors for quantitative methylation analysis. MS-PCR revealed that 55/248 tumors (22.2\%) exhibited BRCA1 promoter hypermethylation. Among the 153 tumors analyzed by both MS-PCR and the EpiTyper ${ }^{\circledR}$ MassARRAY ${ }^{\circledR}$, concordance was 
high $(p<0.001)$, with only four discordant methylation statuses (Figure 2), when the threshold for global methylation percentage was set at 10\% (global methylation percentages of 9.5, 6, 4, and 4).

\subsection{BRCA1 Expression, BRCA1 Promoter Hypermethylation, and Clinicopathological Associations}

Of the 248 TNBC cases assessed for both BRCA1 expression by IHC and BRCA1 promoter hypermethylation using MS-PCR, 55 tumors were hypermethylated. Of these 55, 18 (32.7\%), 9 (16.4\%), and $28(50.9 \%)$ had absent, equivocal, or retained BRCA1 staining, respectively. Of the 193 unmethylated cases, $52(26.9 \%), 4(2.1 \%)$, and $137(71.0 \%)$ had absent, equivocal, or retained BRCA1 staining, respectively. A significant association was found between promoter hypermethylation assessed by MS-PCR and protein expression assessed by IHC, either classified into three categories (retained, equivocal, and absent, $p<0.001$ ) or into two categories (retained vs. equivocal/lost, $p=0.005$ ) (Table 2 ). A trend was found between promoter hypermethylation and a basal-like phenotype (CK5/6 and/or EGFR IHC staining, $p=0.058$ ), and also between BRCA1 expression (BRCA1 absent/equivocal vs. retained) and a basal-like phenotype $(p=0.09)$.

Table 2. Univariate clinicopathological correlations with BRCA1 promoter methylation using MS-PCR.

\begin{tabular}{|c|c|c|c|c|c|}
\hline & \multicolumn{4}{|c|}{$B R C A 1$ Promoter Methylation Status } & \multirow{3}{*}{$p$} \\
\hline & \multicolumn{2}{|l|}{ No } & \multicolumn{2}{|c|}{ Yes } & \\
\hline & $n=193$ & $\%$ & $n=55$ & $\%$ & \\
\hline BRCA1 Methylation (MassARRAY, $n=153$ ) & & & & & $<0.001$ \\
\hline Hypermethylated & 0 & 0 & 31 & 88.6 & \\
\hline Unmethylated & 118 & 100 & 4 & 11.4 & \\
\hline BRCA1 IHC Expression & & & & & $<0.001$ \\
\hline BRCA1- & 52 & 26.9 & 18 & 32.7 & \\
\hline BRCA1+ & 137 & 71.0 & 28 & 50.9 & \\
\hline Equivocal & 4 & 2.1 & 9 & 16.4 & \\
\hline & & & & & 0.005 \\
\hline BRCA1-/ Equivocal & 56 & 29.0 & 27 & 49.1 & \\
\hline BRCA1+ & 137 & 71.0 & 28 & 50.9 & \\
\hline Basal-Like Phetotype & & & & & 0.058 \\
\hline Nul & 48 & 25.1 & 7 & 13.0 & \\
\hline Basal-like & 143 & 74.9 & 47 & 87.0 & \\
\hline PD-L1 Expression (Tumor Cells) & & & & & 0.030 \\
\hline$<1 \%$ & 85 & 47.2 & 15 & 30.0 & \\
\hline$\geq 1 \%$ & 95 & 52.8 & 35 & 70.0 & \\
\hline PD-L1 Expression (Immune Cells) & & & & & 0.011 \\
\hline $0 / 1 / 2$ & 147 & 82.1 & 32 & 65.3 & \\
\hline 3 & 32 & 17.9 & 17 & 34.7 & \\
\hline
\end{tabular}

The Venn diagram (Figure 3) summarizes the cross-distribution of the evaluated population across the three proposed biomarkers of BRCA1 deficiency, i.e., BRCA1 protein expression, BRCA1 promoter hypermethylation, and basal-like phenotype. Among the 248 TNBC cases, three tumors with missing IHC basal marker statuses were excluded from the analysis and only $14.7 \%$ (36/245) of samples did not exhibit any of the three BRCA1 deficiency markers. There is an overlap of TNBC BRCA1-deficient specimens assessed by the three different measures; however, only $25(10.2 \%)$ of the tumors displayed the 3 biomarkers of BRCA1 deficiency. 


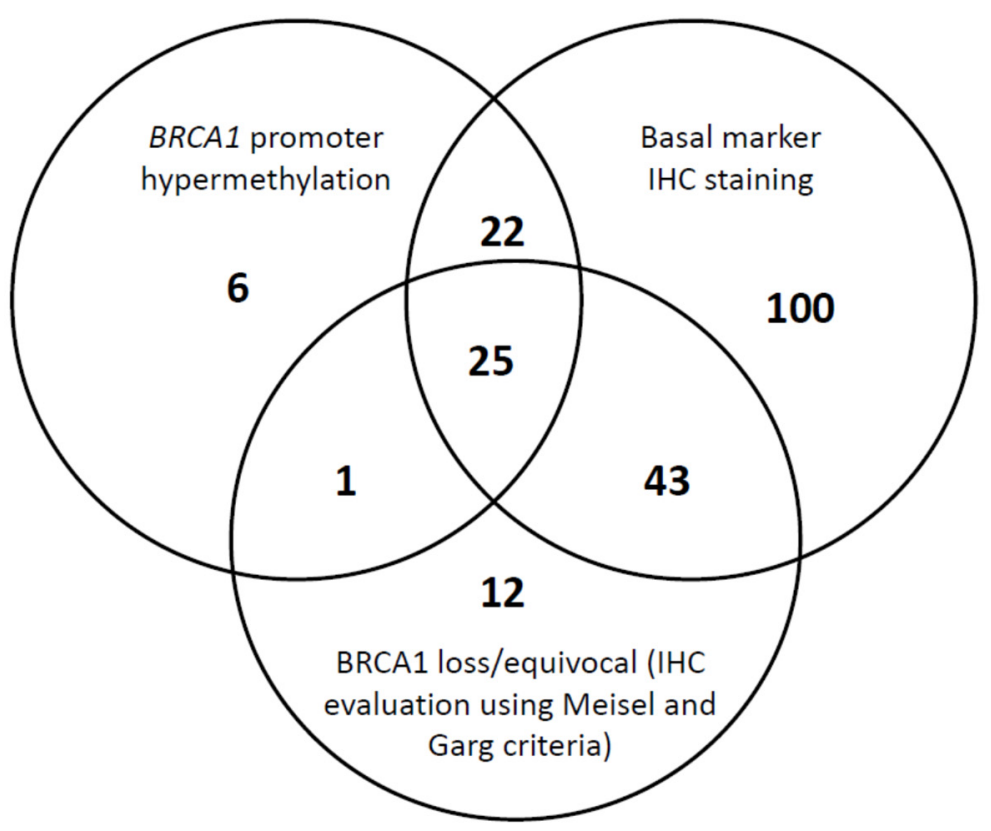

Figure 3. Shared BRCA1 (Breast Cancer 1) deficiency measures in triple negative breast cancers.

Regarding the immune checkpoint protein PD-L1, a significant association was found between BRCA1 promoter hypermethylation and PD-L1 expression by tumor cells, using a $1 \%$ threshold (52.8\% of hypermethylated tumors for tumors with $<1 \%$ cells expressing PD-L1 vs. $70 \%$ for tumors with $\geq 1 \%$ cells expressing PD-L1; $p=0.03)$, or by immune cells using a $50 \%$ threshold $(34.7 \%$ of hypermethylated tumors in score three tumors vs. $17.9 \%$ in tumors with PD-L1 expression score 0-2; $p=0.011)$ (Table 2).

\subsection{Survival Analyses}

Using 24 October 2016 as the cut-off date, the median follow-up was 7.8 years $(95 \%$ CI $[7.3 ; 8.8])$. Seventy-three deaths (five-year overall survival (OS): 80.6\%, 95\% CI [74.9; 85.1]) and 66 relapses occurred (five-year relapse-free survival (RFS): 73.0\%, 95\% CI [66.6;78.4]). The relapse pattern of our population was consistent with the previously reported temporal distribution of relapse risk [1,50], as most relapses occurred during the first three years of follow-up.

Results of the univariate analysis (regarding RFS and OS) in the overall population are summarized in Table 3. High $\mathrm{pT}$ and $\mathrm{pN}$ stages, a lobular subtype, and absence of adjuvant $\mathrm{CT}$ were significantly associated with shorter RFS. The five-year RFS rate was $79.9 \%$ and $71 \%(p=0.112)$ in $B R C A 1$ promoter hypermethylated and non-hypermethylated groups, respectively. For OS, age, pT and pN stages, and the use of adjuvant CT were significant determinants.

In multivariate analysis in the overall population (Table 4A), shorter RFS was significantly associated with high pN stage, no adjuvant CT (5-year RFS: $81 \%$ with vs. $68 \%$ without adjuvant CT, $p=0.038$ ), and histological subtype; OS was significantly associated with $\mathrm{pT}$ and $\mathrm{pN}$ stage, histology, and adjuvant $\mathrm{CT}$. 
Table 3. Univariate analysis.

\begin{tabular}{|c|c|c|c|c|c|c|c|}
\hline \multirow[t]{2}{*}{$(n=248)$} & \multirow[b]{2}{*}{$\mathbf{N}$} & \multicolumn{3}{|c|}{ Relapse-Free Survival (RFS) } & \multicolumn{3}{|c|}{ Oveall Survival (OS) } \\
\hline & & Events & $\begin{array}{l}\text { 5-Year } \\
\text { RFS }\end{array}$ & $\begin{array}{c}\text { Hazard Ratio } \\
{[95 \% \mathrm{CI}]}\end{array}$ & Events & $\begin{array}{l}\text { 5-Year } \\
\text { OS }\end{array}$ & $\begin{array}{c}\text { Hazard Ratio } \\
{[95 \% \mathrm{CI}]}\end{array}$ \\
\hline \multicolumn{8}{|l|}{ Age (Years) } \\
\hline$<55$ & 108 & 23 & 79.6 & 1 & 22 & 87.4 & 1 \\
\hline \multirow[t]{2}{*}{$\geq 55$} & 140 & 43 & 68.0 & $1.52[0.91 ; 2.52]$ & 51 & 75.4 & $2.00[1.21 ; 3.30]$ \\
\hline & & \multicolumn{3}{|c|}{$p=0.103$} & \multicolumn{3}{|c|}{$p=0.005$} \\
\hline \multicolumn{8}{|l|}{ Tumor Size } \\
\hline pT1 & 111 & 16 & 85.3 & 1 & 17 & 90.6 & 1 \\
\hline pT2 & 117 & 39 & 66.9 & $2.46[1.38 ; 4.41]$ & 43 & 75.7 & $2.60[1.48 ; 4.56]$ \\
\hline \multirow[t]{2}{*}{ pT3/pT4 } & 20 & 11 & 44.9 & $4.88[2.26 ; 10.5]$ & 13 & 54.5 & $6.02[2.91 ; 12.4]$ \\
\hline & & \multicolumn{3}{|c|}{$p<0.001$} & \multicolumn{3}{|c|}{$p<0.001$} \\
\hline \multicolumn{8}{|l|}{ Nodal Status } \\
\hline pN- & 162 & 24 & 85.8 & 1 & 35 & 88.9 & 1 \\
\hline \multirow{2}{*}{$\mathrm{pN}+$} & 86 & 42 & 50.9 & $3.94[2.39 ; 6.52]$ & 38 & 65.2 & $2.45[1.55 ; 3.88]$ \\
\hline & & \multicolumn{3}{|c|}{$p<0.001$} & \multicolumn{3}{|c|}{$p<0.001$} \\
\hline \multicolumn{8}{|c|}{ Histological Grade (SBR) } \\
\hline $1-2$ & 59 & 17 & 76.5 & 1 & 20 & 84.3 & 1 \\
\hline \multirow[t]{2}{*}{3} & 185 & 49 & 71.4 & $1.05[0.60 ; 1.82]$ & 52 & 78.9 & $1.05[0.62 ; 1.76]$ \\
\hline & & \multicolumn{3}{|c|}{$p=0.875$} & \multicolumn{3}{|c|}{$p=0.863$} \\
\hline \multicolumn{8}{|l|}{ Histology } \\
\hline Ductal & 204 & 56 & 71.9 & 1 & 65 & 77.8 & 1 \\
\hline Lobular & 12 & 6 & 54.7 & $1.94[0.83 ; 4.50]$ & 4 & 83.3 & $0.99[0.36 ; 2.73]$ \\
\hline Other & 30 & 3 & 89.2 & $0.30[0.09 ; 0.97]$ & 4 & 96.7 & $0.33[0.12 ; 0.92]$ \\
\hline & & & $p=($ & & & $p=($ & \\
\hline Adjuvant Chemotherap & & & & & & & \\
\hline No & 66 & 25 & 60.5 & 1 & 36 & 62.9 & 1 \\
\hline Yes & 181 & 41 & 77.7 & $0.53[0.32 ; 0.87]$ & 37 & 86.9 & $0.34[0.22 ; 0.54]$ \\
\hline & & & $p=($ & & & $p<c$ & \\
\hline Basal-Like Phenotype & & & & & & & \\
\hline $\mathrm{Nul}$ & 55 & 16 & 71.9 & 1 & 18 & 78.8 & 1 \\
\hline Basal-like & 190 & 48 & 73.5 & $0.89[0.50 ; 1.57]$ & 54 & 81.2 & $0.91[0.53 ; 1.55]$ \\
\hline & & & $p=$ & & & $p=($ & \\
\hline BRCA1 IHC Expressior & & & & & & & \\
\hline BRCA1-/Equivocal & 83 & 18 & 79.2 & 1 & 21 & 82.8 & 1 \\
\hline BRCA1+ & 165 & 48 & 69.7 & $1.47[0.85 ; 2.53]$ & 52 & 79.4 & $1.39[0.84 ; 2.31]$ \\
\hline & & & $p=$ & & & $p=c$ & \\
\hline BRCA1 Promoter & & & & & & & \\
\hline Hypermethylation & & & & & & & \\
\hline No & 193 & 56 & 71.0 & 1 & 60 & 79.4 & 1 \\
\hline Yes & 55 & 10 & 79.9 & $0.58[0.30 ; 1.14]$ & 13 & 84.5 & $0.74[0.40 ; 1.34]$ \\
\hline & & & $p=$ & & & $p=$ & \\
\hline PD-L1 expression (tum & & & & & & & \\
\hline$<1 \%$ & 100 & 32 & 69.4 & 1 & 34 & 81.4 & 1 \\
\hline$\geq 1 \%$ & 130 & 30 & 74.4 & $0.74[0.45 ; 1.22]$ & 35 & 79.5 & $0.89[0.56 ; 1.44]$ \\
\hline & & & $p=($ & & & $p=($ & \\
\hline PD-L1 expression (Imm & & & & & & & \\
\hline $0 / 1 / 2$ & 179 & 48 & 73.4 & 1 & 57 & 79.8 & 1 \\
\hline 3 & 49 & 12 & 71.4 & $0.88[0.47 ; 1.66]$ & 10 & 85.9 & $0.66[0.34 ; 1.30]$ \\
\hline & & & $p=(1 \quad p)$ & & & $p=($ & \\
\hline
\end{tabular}

To evaluate the impact of these clinicopathological parameters in patients receiving adjuvant $\mathrm{CT}$, separate multivariate analyses were performed in the populations who received (Table 4B) and who did not receive adjuvant CT (Table 4C).

In the adjuvant CT population (Table $4 \mathrm{~B}$ ), shorter RFS was significantly associated with high $\mathrm{pN}$ stage and BRCA1 promoter hypermethylation $(p=0.021)$; OS was significantly associated with $\mathrm{pT}$ and $\mathrm{pN}$ stage, with a trend for BRCA1 promoter hypermethylation $(p=0.052)$.

In the population without adjuvant CT (Table 4C), shorter RFS was significantly associated with high $\mathrm{pN}$ stage only; OS was significantly associated with $\mathrm{pT}$, $\mathrm{pN}$ stage and histological subtype. 
Table 4. Multivariate analysis (Relapse-Free Sruvival).

\begin{tabular}{|c|c|c|c|c|}
\hline \multicolumn{5}{|c|}{ A. Multivariate analysis: Overall population $(n=248)$} \\
\hline & \multicolumn{2}{|c|}{ Relapse-Free Survival } & \multicolumn{2}{|c|}{ Overall Survival } \\
\hline & Hazard Ratio $[95 \% \mathrm{CI}]$ & $p$-Value & Hazard Ratio $[95 \% \mathrm{CI}]$ & $p$-Value \\
\hline Tumor Size & & & & 0.003 \\
\hline $\mathrm{T} 1$ & & & 1 & \\
\hline $\mathrm{T} 2$ & & & $2.00[1.12 ; 3.59]$ & \\
\hline $\mathrm{T} 3 / \mathrm{T} 4$ & & & $4.21[1.81 ; 9.81]$ & \\
\hline Nodal Status & & $<0.001$ & & 0.003 \\
\hline N- & 1 & & 1 & \\
\hline $\mathrm{N}+$ & $4.99[2.94 ; 8.49]$ & & $2.30[1.35 ; 3.92]$ & \\
\hline Histology & & 0.043 & & 0.005 \\
\hline Ductal & 1 & & 1 & \\
\hline Lobular & $1.11[0.47 ; 2.62]$ & & $0.45[0.15 ; 1.32]$ & \\
\hline Other & $0.30[0.09 ; 0.95]$ & & $0.27[0.09 ; 0.76]$ & \\
\hline $\begin{array}{c}\text { Adjuvant } \\
\text { Chemotherapy }\end{array}$ & & $<0.001$ & & $<0.001$ \\
\hline No & 1 & & 1 & \\
\hline Yes & $0.39[0.23 ; 0.65]$ & & $0.30[0.18 ; 0.48]$ & \\
\hline \multirow{3}{*}{$(n=181)$} & \multicolumn{3}{|c|}{ B. Multivariate Analysis: Adjuvant Chemotherapy = Yes } & \\
\hline & \multicolumn{2}{|c|}{ Relapse-Free Survival } & \multicolumn{2}{|c|}{ Overall Survival } \\
\hline & Hazard Ratio [95\% CI] & p-Value & Hazard Ratio $[95 \%$ CI] & $p$-Value \\
\hline Tumor size & & & & 0.033 \\
\hline $\mathrm{T} 1$ & & & 1 & \\
\hline $\mathrm{T} 2$ & & & $2.74[1.22 ; 6.16]$ & \\
\hline $\mathrm{T} 3 / \mathrm{T} 4$ & & & $2.32[0.65 ; 8.24]$ & \\
\hline Nodal Status & & $<0.001$ & & 0.032 \\
\hline $\mathrm{N}-$ & 1 & & 1 & \\
\hline $\mathrm{N}+$ & $3.50[1.84 ; 6.69]$ & & $2.12[1.06 ; 4.23]$ & \\
\hline $\begin{array}{l}\text { BRCA1 Promoter } \\
\text { Hypermethylation }\end{array}$ & & 0.021 & & 0.052 \\
\hline No & 1 & & 1 & \\
\hline Yes & $0.35[0.12 ; 0.98]$ & & $0.39[0.14 ; 1.13]$ & \\
\hline \multirow{3}{*}{$(n=66)$} & \multirow{2}{*}{\multicolumn{4}{|c|}{ 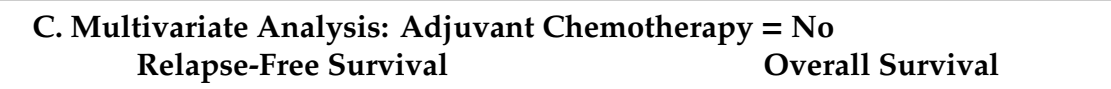 }} \\
\hline & & & & \\
\hline & Hazard Ratio $[95 \%$ CI] & $p$-Value & Hazard Ratio $[95 \% \mathrm{CI}]$ & $p$-Value \\
\hline Tumor Size & & & & 0.017 \\
\hline $\mathrm{T} 1$ & & & 1 & \\
\hline $\mathrm{T} 2$ & & & $1.35[0.58 ; 3.14]$ & \\
\hline $\mathrm{T} 3 / \mathrm{T} 4$ & & & $5.18[1.61 ; 16.7]$ & \\
\hline Nodal Status & & $<0.001$ & & 0.019 \\
\hline $\mathrm{N}-$ & 1 & & 1 & \\
\hline $\mathrm{N}+$ & $6.81[2.99 ; 15.5]$ & & $2.84[1.20 ; 6.70]$ & \\
\hline Histology & & & & 0.020 \\
\hline Ductal & & & 1 & \\
\hline Lobular & & & $0.31[0.07 ; 1.39]$ & \\
\hline Other & & & $0.22[0.05 ; 0.96]$ & \\
\hline
\end{tabular}

As BRCA1 protein expression was not considered in the multivariate analysis ( $p$-value $>0.15$ ), we performed a second multivariate analysis integrating this variable, in order to test the robustness of the results (Table S1). BRCA1 protein expression by IHC was not a statistically significant determinant of prognosis, whatever the population considered, and the previously identified variables remained significant. 
Using the Kaplan-Myer survival curves (Figure 4), adjuvant CT benefit seemed to be restricted to the group of patients with BRCA1-deficient tumors; there was a significant difference between the prognosis of patients affected by an hypermethylated tumor $(p=0.024)$ under adjuvant CT, without difference in patients that did not received adjuvant CT $(p=0.570)$. A trend was seen for adjuvant CT-treated patients in case of BRCA1 negative/equivocal tumors by IHC ( $p=0.092)$, without difference in patients that did not received adjuvant CT $(p=0.595)$. In addition, the independent prognostic information delivered by multivariate analysis of BRCA1 promoter hypermethylation status, and not of IHC-assessed BRCA1 expression, which was also associated with a number of unclassified tumors using the Garg and Meisel criteria (17\%), favors the consideration of BRCA1 promoter hypermethylation status in this TNBC population (Table 3).

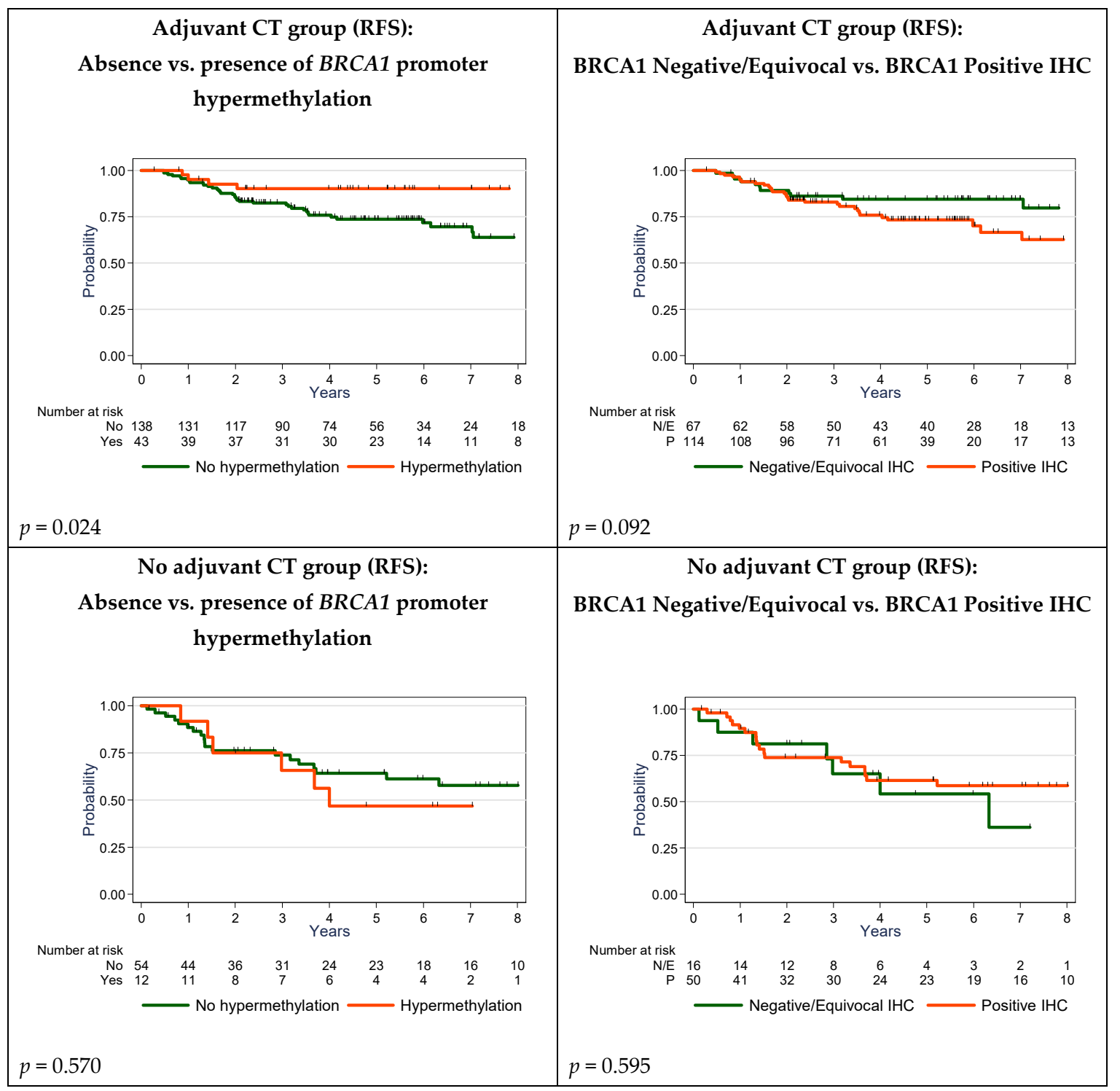

Figure 4. Relapse-Free Survival (RFS) in adjuvant chemotherapy-treated and untreated patients by BRCA1 immunohistochemistry (IHC) expression and BRCA1 promoter hypermethylation.

\section{Discussion}

Comprehensive and accurate determination of BRCA1 expression in TNBCs would allow for informed decisions and the biomarker-driven delivery of effective drugs such as platinum derivatives [51] or PARPi [15]. Here, we report a concomitant analysis of different methods of identifying 
BRCA1 deficiency outside BRCA1 pathogenic variants, their association with clinicopathological characteristics, and their prognostic value in a large homogeneous series of non-metastatic, chemotherapy-naïve TNBCs with a long follow-up. We showed that BRCA1 protein expression, assessed by IHC, correlated with promoter hypermethylation status, and that both were associated with prognosis and CT efficacy. We also showed that IHC analysis was limited and was not a significant independent predictor of RFS in our series. BRCA1 promoter hypermethylation appeared to be the most robust biomarker able to identify a particular subgroup of TNBCs without BRCA1 pathogenic variants, that were associated with a better prognosis and sensitivity to adjuvant CT.

IHC is an efficient, valuable, and inexpensive technique widely used in pathology departments for diagnostic, prognostic, and theragnostic parameters. The identification of TNBCs with defective BRCA1 expression is a major step from a therapeutic point of view, as recently emphasized by the therapeutic impact of PARP $i$ in BRCA1/2-mutated tumors [15,16]. However, to date, there is no definitive recommendation to carry out IHC evaluation of BRCA1 expression in order to robustly screen for pathogenic variants, or to identify additional populations of interest. Whereas some authors [43,49] reported reliable IHC modalities in high-grade serous ovarian carcinomas, others [41,52,53] argue that IHC staining is not robust enough to be used as a screening test for detection of BRCA1 dysfunction. In our hands, this methodology reported a $33.4 \%$ rate of negative/equivocal IHC staining, in accordance with previous data in the high-grade serous ovarian carcinoma population [43,49], but was unable to classify $9.1 \%$ of the tested samples. This failure rate is in accordance with technical limitations reported in the study by Milner et al. [41]

Although we found a significant association between the promoter hypermethylation assessed by the MS-PCR assay and protein expression assessed by IHC, we observed, alongside unclassifiable samples, both false-positive and false-negative cases. Thus, the discordances between the two approaches appear not to be linked to a lack of sensitivity of the antibody used in IHC, but rather to a lack of robustness of the IHC procedure itself, as underlined by Milner et al. [41] Indeed, the sensitivity and specificity of the MS110 monoclonal antibody has been well evaluated, and this antibody, despite its previous use in testing for associations between BRCA1 expression and BRCA1 pathogenic variants (but not promoter hypermethylation), cannot be used as a single marker for the determination of BRCA1 expression levels. Based on these data, we believe that IHC with the MS110 monoclonal antibody cannot be used to detect the epigenetic inactivation of BRCA1 in TNBC.

The 5' end of BRCA1 is embedded in a large CpG-rich region and CpG sites close to the transcription start site that have been shown to contain strong promoter activity [54]. In addition, the hypermethylation of these sites has been associated with reduced BRCA1 protein and mRNA levels [55,56]. Evaluation of the promoter hypermethylation status could help identify more precisely a subgroup of BRCA1-deficient tumors that do not possess BRCA1 pathogenic variants. In this study, we performed qualitative and quantitative methodology to assess the BRCA1 methylation status in 153 tumor samples. Data were highly concordant, with only four conflicting tumor samples (i.e, hypermethylation detected by MS-PCR vs. no hypermethylation detected by the Epityper ${ }^{\circledR}$ MassARRAY ${ }^{\circledR}$ assay), using an arbitrary 10\% methylation threshold for the Epityper ${ }^{\circledR}$ MassARRAY ${ }^{\circledR}$ assay. These discrepancies may be related to the different CPG sites analyzed. Indeed, MS-PCR assessed CpG sites close to the BRCA1 transcription start site, whereas the MassARRAY ${ }^{\circledR}$ approach selected mostly CpG sites in the intron 1 region. Moreover, all four samples identified as hypermethylated by MS-PCR, but as unmethylated by the MassARRAY ${ }^{\circledR}$ platform, had a methylation percentage close to the fixed cut-off value of $10 \%$ for MassARRAY ${ }^{\circledR}$ positivity. Nevertheless, as reported by Kondrashova et al. [57], the level of $B R C A 1$ promoter methylation appears to be important in the context of sensitivity to PARP $i$, and this quantitative method allows a rapid and low-cost analysis of a large number of CpG sites. However, in our series, as shown in Figure 2, tumors with high percentages of methylation were rare $(12(7.84 \%), 9(5.88 \%)$ and $2(1.31 \%)$ tumors if considering 30\%, 35\%, and 50\% cut-offs, respectively). Such low frequency precludes all robust statistical evaluation in our series, and warrants additional evaluation in large cohorts, and in the context of PARP $i$ treatment of breast/ovarian carcinoma. 
In our population, assessment of $B R C A 1$ promoter hypermethylation status identified a population deriving the most benefit from adjuvant CT. The association we identified between BRCA1 promoter hypermethylation and prognosis after adjuvant CT is in accordance with previously published preclinical and clinical data [58,59]. We observed that the patients who benefit most from adjuvant CT are those with BRCA1-defective tumors, validating the results published in 2013 by Xu et al. [60] These results differ from those published by Tutt et al. in the TNT trial [61]. In this randomized phase II trial, BRCA1 promoter hypermethylation was not predictive of an additional benefit of carboplatin over docetaxel in first-line treatment of TNBC. Indeed, BRCA1-defective tumors are known to be more sensitive to platinum salts; however, in this study, the methylation status of the tumors was assessed on archived primary tumors, sampled before patients had received adjuvant CT, and the trial addressed the issue of sensitivity of metastatic disease to first-line CT. A change in the methylation status of the promoter under selection pressure could explain this absence of association. Conversely, in our series, methylation status analysis was performed on the primary tumor, removed some weeks before the initiation of adjuvant CT, and none of our patients had metastatic or pretreated disease. Our results suggest that identification of BRCA1-defective tumors could allow the delivery of adjuvant CT to the sensitive population and avoid its use in the rest of the population, where the prognosis did not differ between patients who received or did not receive adjuvant CT. In our series, only one patient received an adjuvant platinum salts-based chemotherapy. In addition, the tumor was not hypermethylated, and expressed BRCA1 on the IHC evaluation. Thus, our result cannot be the result of an imbalance in platinum salts use between the two groups. Another point to consider is the absence of adjuvant CT in $26.7 \%$ of our population, mainly due to age, histological grade and/or the patient's decision. While these differences between CT-treated and untreated patients could induce a bias in the survival analyses, these specific variables have been tested in the multivariate analysis, and were not retained as independent determinants of prognosis, strengthening our conclusions. Considering these results, reappraisal of the predictive value of $B R C A 1$ promoter methylation status prior to the initiation of $C T$ for metastatic disease appears necessary.

Identifying all defective tumors remains the major challenge. BRCA1 promoter hypermethylation does not represent the only mechanism of BRCA1 deficiency outside pathogenic variants, and patients with tumors with a loss of BRCA1 protein expression derived benefit from adjuvant CT in our series. However, IHC screening failed to identify BRCA1 hypermethylated tumors. It is thus critical to identify other mechanisms responsible for the loss of BRCA1 expression in our population. Id4, a member of the Id (inhibitor of DNA binding) family of proteins, has been demonstrated to downregulate the expression of BRCA1 in in vitro and in-patient tumor samples [62-66]. Other epigenetic regulations, such as microRNAs (miRNAs), could also explain these results. miRNAs are small non-coding RNAs that bind to the 3' untranslated (3'UTR) region of target messenger RNAs (mRNAs); they are known to regulate gene expression and are frequently deregulated in BC. Different miRNAs, such as miR-146, 218, $335,342,498,548$, or 638, regulate BRCA1 mRNA expression, and could contribute to the population of IHC BRCA1-negative tumors [63,67-70]. A critical comprehensive appraisal of these additional factors influencing BRCA1 expression is necessary, in order to better define the tumor population sensitive to CT. Additional efforts are necessary to determine the potential impact of additional events, such as loss of heterozygosity, on the population exhibiting BRCA1 promoter hypermethylation [32].

In the absence of recurrent druggable targets in TNBCs, a considerable effort is presently focused on targeting immune checkpoints in this disease, with significant results [46]. One of the key determinants of immunotherapy activity appears to be linked to the tumor mutational burden and genome instability [47]. We report, to our knowledge for the first time, a significant association between BRCA1 promoter hypermethylation and PD-L1 expression, in both tumor and immune cells. In the study by Sobral-Leite et al., PD-L1 expression showed a modest but significant positive association with the number of silent mutations in TNBC [71]. However, PD-L1 was not associated with BRCA1-like status evaluated using multiplex ligation-dependent probe amplification, an assay unable to identify methylation status. Zhu et al. also did not observe a significant association between 
BRCA1 promoter hypermethylation and PD-L1 expression, in a series of 112 ovarian carcinomas [72]. Our findings, if validated in an independent series, could lead to the use of a combination of treatments targeting synthetic lethality in TNBC, for example by combining a DNA-damaging agent and/or a PARPi to sensitize tumor cells to immune checkpoint inhibitors; such combinations are currently undergoing testing in patients with $B R C A$-mutated tumors. However, a mandatory first step would be a reappraisal of the predictive value of $B R C A 1$ promoter hypermethylation in the context of treatment by PARP inhibitors.

\section{Materials and Methods}

\subsection{Objectives}

The primary endpoint of the study was the evaluation of the robustness of BRCA1 protein expression assessed by IHC to predict BRCA1 promoter methylation status, assessed by the methylation-specific polymerase chain reaction (MS-PCR) assay. The key secondary endpoint was the evaluation of the concordance between the determination of BRCA1 promoter methylation status by the quantitative EpiTyper ${ }^{\circledR}$ MassARRAY ${ }^{\circledR}$ (Agena Bioscience, Sans Diego, CA, USA) and by MS-PCR. Other secondary endpoints were the evaluation of the association between BRCA1 promoter methylation status assessed by MS-PCR and clinicopathological variables, and the evaluation of the impact of these variables on overall survival (OS) and relapse-free survival (RFS).

\subsection{Patients and Tumor Samples}

A total of 1695 consecutive patients with BC, who were referred to our institution between 2002 and 2010, were prospectively entered into the database of a dedicated tumor biobank (Biobank number BB-0033-00059). Samples were isolated from frozen, histologically proven, and macro-dissected invasive BC specimens, that were primarily handled for ER and PR testing using the dextran-coated charcoal (DCC) method, as previously described [73,74], or for uPA/PAI-1 quantification with the Femtelle ${ }^{\circledR}$ test. Tumors were considered ER and PR negative when the receptor concentrations were lower than $10 \mathrm{fmol} / \mathrm{mg}$ of protein (using the DCC assay), or when $<10 \%$ tumor cells were positive for IHC staining [75]. HER2 status was determined based on HER2 protein expression levels evaluated by IHC, using the A485 monoclonal antibody (Dako, Denmark). Tumors with HER2 scores of 0 and $1+$ were considered HER2 negative. In tumors with equivocal HER2 IHC test results (2+), gene amplification was evaluated using fluorescence or chromogenic in situ hybridization. Specimens with HER2 3+ scores were considered HER2 positive. Finally, 248 primary non-metastatic TNBCs, without neoadjuvant treatment, were selected for this study, based on the successful determination of their EGFR, CK5/6, and BRCA1 IHC status, the absence of a known BRCA1 pathogenic variant (patients either tested and without pathogenic variant, or without oncogenetic testing), as well as their BRCA1 promoter methylation status. Each individual treatment proposal was in accordance with our institution guidelines [76]. The clinicopathological characteristics and treatment of the 248 patients included in this study are summarized in Table 1 . This study was reviewed and approved by the Montpellier Cancer Institute Institutional Review Board (ID number ICM-CORT-2015-11). All patients gave their written, informed consent. As part of the study evaluated the prognostic impact of biological markers, this manuscript adheres to the REMARK guidelines.

\subsection{Tissue Microarray and Immunohistochemistry}

Tissue blocks appearing to have enough material upon gross inspection were selected from the Biological Resource Center of the Montpellier Cancer Institute (Biobank number BB-0033-00059). Hematoxylin-eosin-safranin (HES)-stained sections were evaluated by a pathologist for the presence of carcinoma. Two representative tumor areas, to be used for tissue microarray (TMA) construction, were identified on each slide. The tissues corresponding to selected areas were sampled using a manual arraying instrument (Manual Tissue Arrayer 1, Beecher Instruments, Sun Prairie, WI, USA). 
The sampling consisted of two malignant cores ( $1 \mathrm{~mm}$ in diameter) from different areas of the tumor, placed at specified coordinates. When possible, normal breast epithelium was also selected as an internal control. Finally, 349 tumors were sampled in six TMA blocks. After completion of the arraying process, TMA blocks were sectioned at a thickness of $4 \mu \mathrm{m}$. One section was stained with HES and the others were used for IHC. TMA sections to be stained for BRCA1, CK5/6, or PD-L1 underwent PTLink pre-treatment (Dako/Agilent, Santa Clara, CA, USA), allowing simultaneous de-paraffinization and antigen retrieval. Heat-induced antigen retrieval was executed for $15 \mathrm{~min}$ in High $\mathrm{pH} \mathrm{Buffer}$ (Dako/Agilent, Santa Clara, CA, USA) at $95^{\circ} \mathrm{C}$. TMA sections to be stained for EGFR were deparaffinized and rehydrated prior to antigen retrieval with proteinase $\mathrm{K}$. Following antigen retrieval, endogenous peroxidase was quenched using Flex Peroxidase Block (Dako/Agilent, Santa Clara, CA, USA), for 5 min at room temperature. Slides were then incubated at room temperature with antibodies raised against human BRCA1 (mouse monoclonal, clone MS110, 1:100, 20 min, Calbiochem, San Diego, CA, USA), human CK 5/6 (mouse monoclonal, clone 6D5/16 B4, 1:100, 20 min, Dako/Agilent, Santa Clara, CA, USA), human PD-L1 (rabbit monoclonal, clone SP142, 1:200, 30 min, Roche, Penzberg, Germany), or human EGFR (mouse monoclonal, clone 31G7, 1:50, 20 min, Invitrogen, Carlsbad, CA, USA). An amplification step was used for BRCA1 and PD-L1 immunostaining (mouse or rabbit linker, respectively, Dako/Agilent, Santa Clara, CA, USA). After two rinses in buffer, the slides were incubated with a horseradish peroxidase-labeled polymer coupled to secondary anti-mouse and anti-rabbit antibodies for $20 \mathrm{~min}$, followed by application of 3,3'-diaminobenzidine for $10 \mathrm{~min}$ as a substrate. Counterstaining was performed using Flex Hematoxylin (Dako/Agilent, Santa Clara, CA, USA), after which slides were washed under tap water for $5 \mathrm{~min}$. Finally, slides were mounted with a coverslip after dehydration.

\subsection{TMA Analysis/Interpretation}

TMA sections were analyzed independently by two trained observers, both blinded to the clinicopathological characteristics and patient outcomes at the time of scoring. For BRCA1 staining, the percentages of stained nuclei at each intensity (weak, moderate, and strong) were collected and used to score each tumor as BRCA1 loss, BRCA1 equivocal, or BRCA1 retained, following the Garg and Meisel criteria [43,49]. In the case of disagreement, the BRCA status was determined by consensus after simultaneous dual reexamination. Stromal cells served as internal positive controls and validated the staining. If BRCA1 expression was scored as absent or equivocal, the BRCA1 IHC procedure was carried out on corresponding full-face tissue sections, followed by the same scoring procedure, and scores obtained in the whole section were used. CK 5/6 and EGFR expression was scored according to the percentage of positive tumor cells, irrespective of the staining intensity. Tumors were determined as basal-like if $\geq 1 \%$ of tumor cells expressed CK5/6 and/or EGFR. PD-L1 expression was evaluated independently in invasive cancer cells (percentage of tumor cells exhibiting membranous staining, regardless of its intensity) and the immune cell component (percentage of PD-L1-positive cells, regardless of its cellular localization or intensity; specimens were scored as $0,1,2$, or 3 if $0 \%$, $<10 \%, 10-50 \%$, or $\geq 50 \%$ of immune cells were PD-L1-positive, respectively).

\subsection{Tissue Processing and DNA Extraction}

DNA was extracted from frozen tumor tissue samples, as previously described $[25,73]$, with the QIAamp DNA Mini Kit (Qiagen GmbH, Hilden, Germany), according to the manufacturer's instructions.

\subsection{BRCA1 Promoter Methylation Status}

DNA methylation patterns at the CpG islands of the BRCA1 promoter were assessed, using the MS-PCR assay previously described [25,32,77]. This method distinguishes between unmethylated and hypermethylated alleles on the basis of sequence changes following bisulfite treatment of DNA, that converts only unmethylated cytosines to uracil. Bisulfite treatment was performed using the EpiTect 
Bisulfite Kit (Qiagen GmbH, Hilden, Germany). PCRs were performed on an Eppendorf Mastercycler ${ }^{\circledR}$ (Eppendorf, Hamburg, Germany), with the EpiTect MSP-PCR Kit (QIAGEN GmbH, Hilden, Germany), and specific primers designed for hypermethylated or unmethylated BRCA1 DNA sequences [32]. This MS-PCR analyzed a total of seven CpG sites, located at $-37,-29,-21,-19,+16,+19$, and +27 , relative to the $B R C A 1$ exon $1 \mathrm{~A}$ transcription start site (Figure 1). The primers for the methylated reaction generated a 75-bp-long amplicon and the primers for the unmethylated amplified an 86-bp-long product. The EpiTect PCR Control DNA Set (Qiagen Hindel, Germany), containing both bisulfite-converted methylated and unmethylated DNA and unconverted unmethylated DNA, were also added as MS-PCR controls. Seven $\mu \mathrm{L}$ of each PCR product was loaded directly onto an $1 \%$ agarose $+3 \%$ NuSieve GTG agarose gel, stained with $1 \mu \mathrm{L} / 10 \mathrm{~mL}$ SYBR ${ }^{\circledR}$ Safe DNA gel stain, and visualized under UV light. Samples were scored as hypermethylated only when a distinct band was present on the gel. If DNA samples presented low-intensity bands in the agarose gel, PCR with 6-FAM ${ }^{\mathrm{TM}}$-labeled or HEX ${ }^{\mathrm{TM}}$-labeled forward primers, amplifying specifically hypermethylated or unmethylated sequences, respectively, was carried out. DNA fragment analysis was performed by capillary electrophoresis on an Applied Biosystems 3130 Genetic Analyzer. Analyses were conducted with the GeneMapper Software v3.7 (Apllied Biosystems, Foster City, CA, USA).

The biochemistry of the EpiTyper ${ }^{\circledR}$ MassARRAY ${ }^{\circledR}$ starts with the bisulfite treatment of genomic DNA, followed by PCR amplification of target regions. The reverse primers contain a T7 promoter tag. Next, in vitro RNA transcription is performed, followed by base-specific RNA cleavage. Finally, the cleavage products are analyzed using MALDI-TOF mass spectrometry (MassARRAY Analyzer). The methylated and unmethylated cytosine residues in the original genomic DNA are easily distinguished using EpiTYPER Software. Three amplicons were analyzed to cover 13 CpGs sites, located at $-166,-134$, $-127,+177,+195,+222,+235,+256,+292,+294,+399,+402$, and +457 , relative to the BRCA1 exon $1 \mathrm{~A}$ transcription start site (Figure 5).

NBR2

BRCA1

A

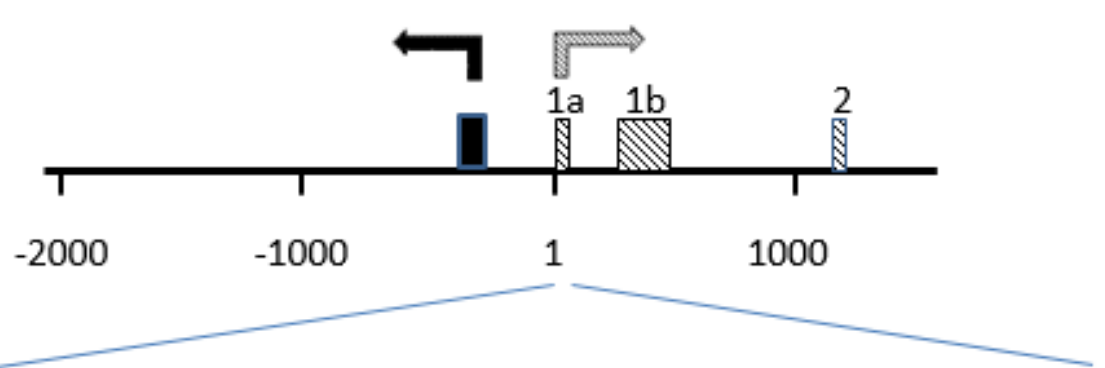

B

ttccgtctctttccttttacgtcatcegggggcagactgggtggccaatccagagcccegagagacgcttggctctttctgtc cctcccatcctctgattGTACCTTGATTTCGTATTCTGAGAGGCTGCTGCTTAGCGGTAGCCCCTTGG

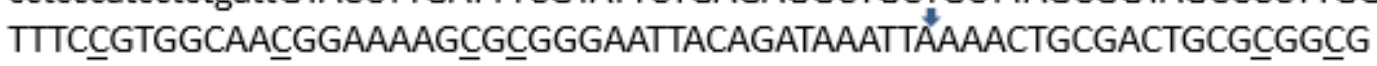
TGAGCTCGCTGAGACTTCCTGGACGGGGGACAGGCTGTGGGGTTTCTCAGATAACTGGGCC CCTGCGCTCAGGAGGCCTTCACCCTCTGCTCTGGGTAAAGgtagtagagtcccgggaaagggacagg gggcccaagtgatgctctggggtactggcgtgggagagtggatttccaagctgacagatgggtattctttgacgggggg taggggcggaacctgagaggcgtaaggcgttgtgaacctggggaggggggcagtttgtaggtcgcgagggaagcgct gaggatcaggaagggggcactgagtgtccgtgggggaatcctcgtgataggaactggaatatgccttgagggggacac tatgtctttaaaaacgtcggctggtcatgaggtcaggagttccagaccagcctgaccaacgtggtgaaactccgtctct

Figure 5. Distribution of $C p G$ sites analyzed in the promoter region of the BRCA1 gene. (A) The BRCA1-NBR2 locus: the position of the first exons of the BRCA1 is indicated by shaded boxes. The first exon of NBR2 gene is indicated by a black box. (B) Position of CpG sites analyzed Cytosine on CpG sites tested by MS-PCR are underlined. Cytosine on CpG sites tested by MassARRAY@EpiTYPER@assay are in bold. The positive strand of the BRCA1 gene is shown based on GenBank accession number U37574. The transcription start site of the BRCA1 exon 1A is marked by an arrow. Exon 1A sequence is in capital, and both 5'upstream sequence and intron 1 sequence are in lower case characters. 


\subsection{Statistical Analysis}

Categorical variables were presented as frequency distributions, and continuous variables as medians and ranges. Categorical variables were compared with the Pearson's chi-square or Fisher's exact test. OS was defined as the time between the date of surgery and the date of death (whatever the cause). Patients lost to follow-up were censored at the last documented visit. RFS was defined as the time between the date of surgery and the date of recurrence. Patients alive at the last follow-up without recurrence and patients lost to follow-up were censored at the last documented visit. Patients who died without recurrence were censored at the date of death. The Kaplan-Meier method was used to estimate the OS and RFS rates. Differences in survival rates were compared using the log-rank test. Multivariate analyses were performed using the Cox proportional hazard model, using variables with a $p$-value $<0.15$ in univariate analysis. Hazard ratios (HR) are given with their $95 \%$ confidence interval (95\% CI). Statistical analyses were performed with STATA 13.0 (StatCorp, College Station, TX, USA).

\section{Conclusions}

$B R C A 1$ promoter hypermethylation is associated with basal-like features and PD-L1 expression, and is independently associated with a better prognosis in TNBC, especially in the subgroup of patients treated with adjuvant CT. IHC evaluation of BRCA1 expression appears to be difficult to standardize and implement, considering the impact of the pre-analytical and analytical variables, even though the detected protein expression appears to be associated with the BRCA1 hypermethylation status of the tumors. In our series, it did not appear to be independently associated with prognosis. The association between promoter hypermethylation and sensitivity to PARP inhibitors needs to be evaluated in a specific series of patients.

Supplementary Materials: The following are available online at http://www.mdpi.com/2072-6694/12/4/828/s1, Table S1: (1A). Multivariate analysis including BRCA1 IHC expression: Overall population $(\mathrm{N}=245),(\mathbf{1 B})$. Multivariate analysis including BRCA1 IHC expression: Adjuvant Chemotherapy = Yes, (1C). Multivariate analysis including BRCA1 IHC expression: Adjuvant Chemotherapy = No. Figure S1: Examples of BRCA1-immunostained triple negative breast cancers. (A): loss of BRCA1 expression in tumor cells with the presence of positive internal controls (arrows); (B): equivocal BRCA1 expression with weak staining intensity of positive tumor cell nuclei (arrow heads) with the presence of positive internal controls (arrows); (C): retained BRCA1 expression with numerous strongly positive tumor cell nuclei. Immunoperoxydase $x 400$.

Author Contributions: W.J. participated in the conception and design of the study, provided study patients and material, collected, assembled and interpreted the data, and drafted the manuscript. E.L.-C. carried out the assays, collected and assembled the data, and helped to draft the manuscript. C.M. participated in the conception and design of the study and performed the statistical analysis. F.B.-M. provided study patients and material, collected and assembled the data, carried out the assays, and helped to draft the manuscript. J.S.-L. performed the pathological evaluation and helped to draft the manuscript. A.H.-P.-C. designed some of the assays, carried out the assays, collected and assembled the data, and helped to draft the manuscript. E.C. collected and assembled the data and helped to draft the manuscript. C.T. participated in the conception and design of the study, interpreted the data, and helped to draft the manuscript. J.S.-L. performed the pathological evaluation. A.L. designed some of the assays, carried out the assays, collected and assembled the data, and helped to draft the manuscript. R.S. designed some of the assays, carried out the assays, collected and assembled the data, and helped to draft the manuscript. P.-J.L. participated in the conception and design of the study, provided study material, and helped to draft the manuscript. S.G. participated in the conception and design of the study, provided study patients and material, and helped to draft the manuscript. All authors have read and agreed to the published version of the manuscript.

Funding: This study was sponsored by an unrestricted research grant from AstraZeneca and from the Aude and Hérault French Ligue contre le Cancer. The funding body did not influence the design of the study; the collection, analysis, and interpretation of data; or the writing of the manuscript.

Acknowledgments: The authors thank Hélène de Forges, Ph.D., for her editorial assistance.

Conflicts of Interest: WJ: Research funding (Astra Zeneca), honoraria (Astra Zeneca, Pfizer), travel grants (Astra Zeneca, Pfizer). PJL: Grants (Agena Bioscience), honoraria (AstraZeneca, Bristol Meyer Squibb, Roche, Agena Bioscience). All other authors declare that they have no competing interests. 


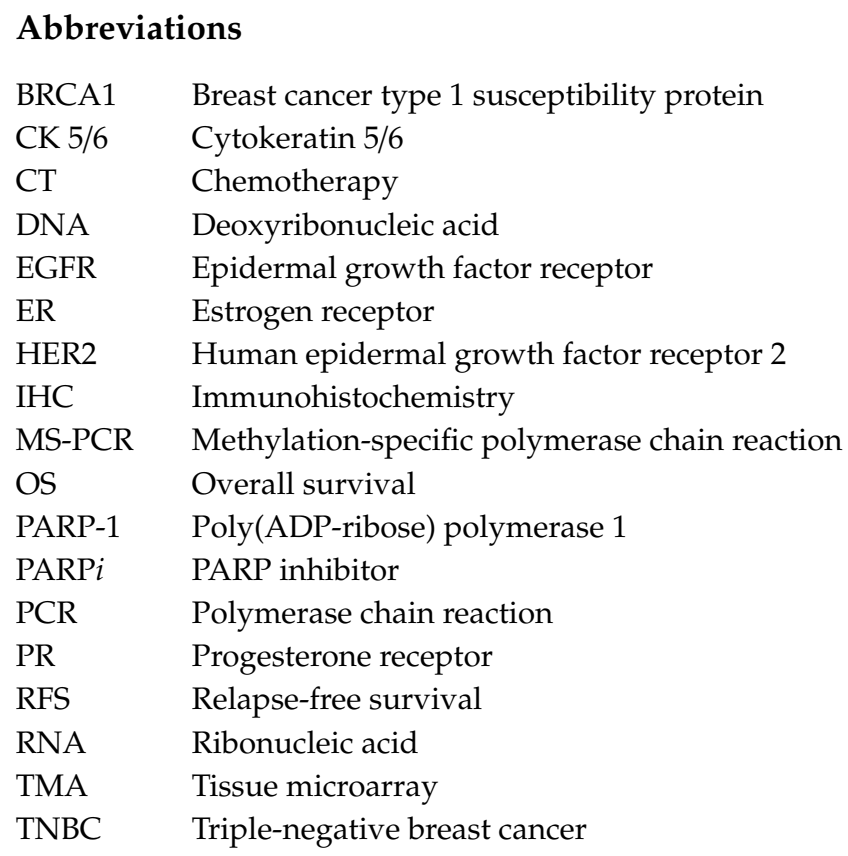

\section{References}

1. Dent, R.; Trudeau, M.; Pritchard, K.I.; Hanna, W.M.; Kahn, H.K.; Sawka, C.A.; Lickley, L.A.; Rawlinson, E.; Sun, P.; Narod, S.A. Triple-negative breast cancer: Clinical features and patterns of recurrence. Clin. Cancer Res. Off. J. Am. Assoc. Cancer Res. 2007, 13, 4429-4434. [CrossRef] [PubMed]

2. Elias, A.D. Triple-negative breast cancer: A short review. Am. J. Clin. Oncol. 2010, 33, 637-645. [CrossRef] [PubMed]

3. Carey, L.A.; Dees, E.C.; Sawyer, L.; Gatti, L.; Moore, D.T.; Collichio, F.; Ollila, D.W.; Sartor, C.I.; Graham, M.L.; Perou, C.M. The triple negative paradox: Primary tumor chemosensitivity of breast cancer subtypes. Clin. Cancer Res. 2007, 13, 2329-2334. [CrossRef] [PubMed]

4. Perou, C.M.; Sorlie, T.; Eisen, M.B.; van de Rijn, M.; Jeffrey, S.S.; Rees, C.A.; Pollack, J.R.; Ross, D.T.; Johnsen, H.; Akslen, L.A.; et al. Molecular portraits of human breast tumours. Nature 2000, 406, 747-752. [CrossRef]

5. Sorlie, T.; Perou, C.M.; Tibshirani, R.; Aas, T.; Geisler, S.; Johnsen, H.; Hastie, T.; Eisen, M.B.; van de Rijn, M.; Jeffrey, S.S.; et al. Gene expression patterns of breast carcinomas distinguish tumor subclasses with clinical implications. Proc. Natl. Acad. Sci. USA 2001, 98, 10869-10874. [CrossRef]

6. Prat, A.; Adamo, B.; Cheang, M.C.; Anders, C.K.; Carey, L.A.; Perou, C.M. Molecular characterization of basal-like and non-basal-like triple-negative breast cancer. Oncologist 2013, 18, 123-133. [CrossRef]

7. Cheang, M.C.; Voduc, D.; Bajdik, C.; Leung, S.; McKinney, S.; Chia, S.K.; Perou, C.M.; Nielsen, T.O. Basal-like breast cancer defined by five biomarkers has superior prognostic value than triple-negative phenotype. Clin. Cancer Res. Off. J. Am. Assoc. Cancer Res. 2008, 14, 1368-1376. [CrossRef]

8. Lakhani, S.R.; Van De Vijver, M.J.; Jacquemier, J.; Anderson, T.J.; Osin, P.P.; McGuffog, L.; Easton, D.F. The pathology of familial breast cancer: Predictive value of immunohistochemical markers estrogen receptor, progesterone receptor, HER-2, and p53 in patients with mutations in BRCA1 and BRCA2. J. Clin. Oncol. 2002, 20, 2310-2318. [CrossRef]

9. Stevens, K.N.; Vachon, C.M.; Couch, F.J. Genetic susceptibility to triple-negative breast cancer. Cancer Res. 2013, 73, 2025-2030. [CrossRef]

10. Song, Y.; Barry, W.T.; Seah, D.S.; Tung, N.M.; Garber, J.E.; Lin, N.U. Patterns of recurrence and metastasis in BRCA1/BRCA2-associated breast cancers. Cancer 2020, 126, 271-280. [CrossRef]

11. Turner, N.; Tutt, A.; Ashworth, A. Hallmarks of 'BRCAness' in sporadic cancers. Nat. Rev. Cancer 2004, 4, 814-819. [CrossRef] [PubMed]

12. Liu, X.; Palma, J.; Kinders, R.; Shi, Y.; Donawho, C.; Ellis, P.A.; Rodriguez, L.E.; Colon-Lopez, M.; Saltarelli, M.; LeBlond, D.; et al. An enzyme-linked immunosorbent poly (ADP-ribose) polymerase biomarker assay for clinical trials of PARP inhibitors. Anal. Biochem. 2008, 381, 240-247. [CrossRef] [PubMed] 
13. Helleday, T.; Petermann, E.; Lundin, C.; Hodgson, B.; Sharma, R.A. DNA repair pathways as targets for cancer therapy. Nat. Rev. Cancer 2008, 8, 193-204. [CrossRef] [PubMed]

14. Tutt, A.; Robson, M.; Garber, J.E.; Domchek, S.M.; Audeh, M.W.; Weitzel, J.N.; Friedlander, M.; Arun, B.; Loman, N.; Schmutzler, R.K.; et al. Oral poly(ADP-ribose) polymerase inhibitor olaparib in patients with BRCA1 or BRCA2 mutations and advanced breast cancer: A proof-of-concept trial. Lancet 2010, 376, 235-244. [CrossRef]

15. Robson, M.; Im, S.A.; Senkus, E.; Xu, B.; Domchek, S.M.; Masuda, N.; Delaloge, S.; Li, W.; Tung, N.; Armstrong, A.; et al. Olaparib for Metastatic Breast Cancer in Patients with a Germline BRCA Mutation. N. Engl. J. Med. 2017, 377, 523-533. [CrossRef]

16. Litton, J.K.; Rugo, H.S.; Ettl, J.; Hurvitz, S.A.; Goncalves, A.; Lee, K.H.; Fehrenbacher, L.; Yerushalmi, R.; Mina, L.A.; Martin, M.; et al. Talazoparib in Patients with Advanced Breast Cancer and a Germline BRCA Mutation. N. Engl. J. Med. 2018, 379, 753-763. [CrossRef]

17. Rakha, E.A.; El-Sheikh, S.E.; Kandil, M.A.; El-Sayed, M.E.; Green, A.R.; Ellis, I.O. Expression of BRCA1 protein in breast cancer and its prognostic significance. Hum. Pathol. 2008, 39, 857-865. [CrossRef]

18. Bal, A.; Verma, S.; Joshi, K.; Singla, A.; Thakur, R.; Arora, S.; Singh, G. BRCA1-methylated sporadic breast cancers are BRCA-like in showing a basal phenotype and absence of ER expression. Virchows Arch. 2012, 461, 305-312. [CrossRef]

19. Birgisdottir, V.; Stefansson, O.A.; Bodvarsdottir, S.K.; Hilmarsdottir, H.; Jonasson, J.G.; Eyfjord, J.E. Epigenetic silencing and deletion of the BRCA1 gene in sporadic breast cancer. Breast Cancer Res. BCR 2006, 8, R38. [CrossRef]

20. Lips, E.H.; Mulder, L.; Hannemann, J.; Laddach, N.; Vrancken Peeters, M.T.; van de Vijver, M.J.; Wesseling, J.; Nederlof, P.M.; Rodenhuis, S. Indicators of homologous recombination deficiency in breast cancer and association with response to neoadjuvant chemotherapy. Ann. Oncol. Off. J. Eur. Soc. Med. Oncol. ESMO 2011, 22, 870-876. [CrossRef]

21. Mirza, S.; Sharma, G.; Prasad, C.P.; Parshad, R.; Srivastava, A.; Gupta, S.D.; Ralhan, R. Promoter hypermethylation of TMS1, BRCA1, ERalpha and PRB in serum and tumor DNA of invasive ductal breast carcinoma patients. Life Sci. 2007, 81, 280-287. [CrossRef] [PubMed]

22. Wei, M.; Grushko, T.A.; Dignam, J.; Hagos, F.; Nanda, R.; Sveen, L.; Xu, J.; Fackenthal, J.; Tretiakova, M.; Das, S.; et al. BRCA1 promoter methylation in sporadic breast cancer is associated with reduced BRCA1 copy number and chromosome 17 aneusomy. Cancer Res. 2005, 65, 10692-10699. [CrossRef] [PubMed]

23. Lips, E.H.; Mulder, L.; Oonk, A.; van der Kolk, L.E.; Hogervorst, F.B.; Imholz, A.L.; Wesseling, J.; Rodenhuis, S.; Nederlof, P.M. Triple-negative breast cancer: BRCAness and concordance of clinical features with BRCA1-mutation carriers. Br. J. Cancer 2013, 108, 2172-2177. [CrossRef] [PubMed]

24. Birkbak, N.J.; Wang, Z.C.; Kim, J.Y.; Eklund, A.C.; Li, Q.; Tian, R.; Bowman-Colin, C.; Li, Y.; Greene-Colozzi, A.; Iglehart, J.D.; et al. Telomeric allelic imbalance indicates defective DNA repair and sensitivity to DNA-damaging agents. Cancer Discov. 2012, 2, 366-375. [CrossRef]

25. Jacot, W.; Thezenas, S.; Senal, R.; Viglianti, C.; Laberenne, A.C.; Lopez-Crapez, E.; Bibeau, F.; Bleuse, J.P.; Romieu, G.; Lamy, P.J. BRCA1 promoter hypermethylation, 53BP1 protein expression and PARP-1 activity as biomarkers of DNA repair deficit in breast cancer. BMC Cancer 2013, 13, 523. [CrossRef]

26. Zhang, L.; Long, X. Association of BRCA1 promoter methylation with sporadic breast cancers: Evidence from 40 studies. Sci. Rep. 2015, 5, 17869. [CrossRef]

27. Yamashita, N.; Tokunaga, E.; Kitao, H.; Hitchins, M.; Inoue, Y.; Tanaka, K.; Hisamatsu, Y.; Taketani, K.; Akiyoshi, S.; Okada, S.; et al. Epigenetic Inactivation of BRCA1 Through Promoter Hypermethylation and Its Clinical Importance in Triple-Negative Breast Cancer. Clin. Breast Cancer 2015, 15, 498-504. [CrossRef]

28. Zhu, X.; Shan, L.; Wang, F.; Wang, J.; Wang, F.; Shen, G.; Liu, X.; Wang, B.; Yuan, Y.; Ying, J.; et al. Hypermethylation of BRCA1 gene: Implication for prognostic biomarker and therapeutic target in sporadic primary triple-negative breast cancer. Breast Cancer Res. Treat. 2015, 150, 479-486. [CrossRef]

29. Cai, F.F.; Chen, S.; Wang, M.H.; Lin, X.Y.; Zhang, L.; Zhang, J.X.; Wang, L.X.; Yang, J.; Ding, J.H.; Pan, X.; et al. Pyrosequencing quantified methylation level of BRCA1 promoter as prognostic factor for survival in breast cancer patient. Oncotarget 2016, 7, 27499-27510. [CrossRef] 
30. Sun, T.; Ruscito, I.; Dimitrova, D.; Chekerov, R.; Kulbe, H.; Baron, U.; Blanchard, V.; Panici, P.B.; Darb-Esfahani, S.; Sehouli, J.; et al. Genetic Versus Epigenetic BRCA1 Silencing Pathways: Clinical Effects in Primary Ovarian Cancer Patients: A Study of the Tumor Bank Ovarian Cancer Consortium. Int. J. Gynecol. Cancer 2017. [CrossRef]

31. Cancer Genome Atlas Research, N. Integrated genomic analyses of ovarian carcinoma. Nature 2011, 474, 609-615. [CrossRef] [PubMed]

32. Esteller, M.; Silva, J.M.; Dominguez, G.; Bonilla, F.; Matias-Guiu, X.; Lerma, E.; Bussaglia, E.; Prat, J.; Harkes, I.C.; Repasky, E.A.; et al. Promoter hypermethylation and BRCA1 inactivation in sporadic breast and ovarian tumors. J. Natl. Cancer Inst. 2000, 92, 564-569. [CrossRef] [PubMed]

33. Yang, D.; Khan, S.; Sun, Y.; Hess, K.; Shmulevich, I.; Sood, A.K.; Zhang, W. Association of BRCA1 and BRCA2 mutations with survival, chemotherapy sensitivity, and gene mutator phenotype in patients with ovarian cancer. JAMA 2011, 306, 1557-1565. [CrossRef] [PubMed]

34. Bol, G.M.; Suijkerbuijk, K.P.; Bart, J.; Vooijs, M.; van der Wall, E.; van Diest, P.J. Methylation profiles of hereditary and sporadic ovarian cancer. Histopathology 2010, 57, 363-370. [CrossRef] [PubMed]

35. Evans, D.G.R.; van Veen, E.M.; Byers, H.J.; Wallace, A.J.; Ellingford, J.M.; Beaman, G.; Santoyo-Lopez, J.; Aitman, T.J.; Eccles, D.M.; Lalloo, F.I.; et al. A Dominantly Inherited 5' UTR Variant Causing Methylation-Associated Silencing of BRCA1 as a Cause of Breast and Ovarian Cancer. Am. J. Hum. Genet. 2018, 103, 213-220. [CrossRef] [PubMed]

36. Collins, N.; Wooster, R.; Stratton, M.R. Absence of methylation of CpG dinucleotides within the promoter of the breast cancer susceptibility gene BRCA2 in normal tissues and in breast and ovarian cancers. Br. J. Cancer 1997, 76, 1150-1156. [CrossRef] [PubMed]

37. Hughes-Davies, L.; Huntsman, D.; Ruas, M.; Fuks, F.; Bye, J.; Chin, S.F.; Milner, J.; Brown, L.A.; Hsu, F.; Gilks, B.; et al. EMSY links the BRCA2 pathway to sporadic breast and ovarian cancer. Cell 2003, 115, 523-535. [CrossRef]

38. Gelmon, K.A.; Tischkowitz, M.; Mackay, H.; Swenerton, K.; Robidoux, A.; Tonkin, K.; Hirte, H.; Huntsman, D.; Clemons, M.; Gilks, B.; et al. Olaparib in patients with recurrent high-grade serous or poorly differentiated ovarian carcinoma or triple-negative breast cancer: A phase 2, multicentre, open-label, non-randomised study. Lancet Oncol. 2011, 12, 852-861. [CrossRef]

39. Drew, Y.; Mulligan, E.A.; Vong, W.T.; Thomas, H.D.; Kahn, S.; Kyle, S.; Mukhopadhyay, A.; Los, G.; Hostomsky, Z.; Plummer, E.R.; et al. Therapeutic potential of poly(ADP-ribose) polymerase inhibitor AG014699 in human cancers with mutated or methylated BRCA1 or BRCA2. J. Natl. Cancer Inst. 2011, 103, 334-346. [CrossRef]

40. Veeck, J.; Ropero, S.; Setien, F.; Gonzalez-Suarez, E.; Osorio, A.; Benitez, J.; Herman, J.G.; Esteller, M. BRCA1 CpG island hypermethylation predicts sensitivity to poly(adenosine diphosphate)-ribose polymerase inhibitors. J. Clin. Oncol. 2010, 28, e563-e564. [CrossRef]

41. Milner, R.; Wombwell, H.; Eckersley, S.; Barnes, D.; Warwicker, J.; Van Dorp, E.; Rowlinson, R.; Dearden, S.; Hughes, G.; Harbron, C.; et al. Validation of the BRCA1 antibody MS110 and the utility of BRCA1 as a patient selection biomarker in immunohistochemical analysis of breast and ovarian tumours. Virchows Arch. 2013, 462, 269-279. [CrossRef] [PubMed]

42. Al-Mulla, F.; Abdulrahman, M.; Varadharaj, G.; Akhter, N.; Anim, J.T. BRCA1 gene expression in breast cancer: A correlative study between real-time RT-PCR and immunohistochemistry. J. Histochem. Cytochem. 2005, 53, 621-629. [CrossRef] [PubMed]

43. Meisel, J.L.; Hyman, D.M.; Garg, K.; Zhou, Q.; Dao, F.; Bisogna, M.; Gao, J.; Schultz, N.D.; Grisham, R.N.; Phillips, M.; et al. The performance of BRCA1 immunohistochemistry for detecting germline, somatic, and epigenetic BRCA1 loss in high-grade serous ovarian cancer. Ann. Oncol. Off. J. Eur. Soc. Med. Oncol. ESMO 2014, 25, 2372-2378. [CrossRef] [PubMed]

44. Korlimarla, A.; Prabhu, J.S.; Remacle, J.; Rajarajan, S.; Raja, U.; Ce, A.; Srinath, B.S.; Manjunath, S.; Ks, G.; Correa, M.; et al. Identification of BRCA1 Deficiency Using Multi-Analyte Estimation of BRCA1 and Its Repressors in FFPE Tumor Samples from Patients with Triple Negative Breast Cancer. PLoS ONE 2016, 11, e0153113. [CrossRef] [PubMed]

45. Guo, T.; Ren, Y.; Wang, B.; Huang, Y.; Jia, S.; Tang, W.; Luo, Y. Promoter methylation of BRCA1 is associated with estrogen, progesterone and human epidermal growth factor receptor-negative tumors and the prognosis of breast cancer: A meta-analysis. Mol. Clin. Oncol. 2015, 3, 1353-1360. [CrossRef] [PubMed] 
46. Schmid, P.; Chui, S.Y.; Emens, L.A. Atezolizumab and Nab-Paclitaxel in Advanced Triple-Negative Breast Cancer. Reply. N. Engl. J. Med. 2019, 380, 987-988. [CrossRef]

47. Yarchoan, M.; Hopkins, A.; Jaffee, E.M. Tumor Mutational Burden and Response Rate to PD-1 Inhibition. N. Engl. J. Med. 2017, 377, 2500-2501. [CrossRef]

48. Mittendorf, E.A.; Philips, A.V.; Meric-Bernstam, F.; Qiao, N.; Wu, Y.; Harrington, S.; Su, X.; Wang, Y.; Gonzalez-Angulo, A.M.; Akcakanat, A.; et al. PD-L1 Expression in Triple-Negative Breast Cancer. Cancer Immunol. Res. 2014, 2, 361-370. [CrossRef]

49. Garg, K.; Levine, D.A.; Olvera, N.; Dao, F.; Bisogna, M.; Secord, A.A.; Berchuck, A.; Cerami, E.; Schultz, N.; Soslow, R.A. BRCA1 immunohistochemistry in a molecularly characterized cohort of ovarian high-grade serous carcinomas. Am. J. Surg. Pathol. 2013, 37, 138-146. [CrossRef]

50. Cho, E.Y.; Chang, M.H.; Choi, Y.L.; Lee, J.E.; Nam, S.J.; Yang, J.H.; Park, Y.H.; Ahn, J.S.; Im, Y.H. Potential candidate biomarkers for heterogeneity in triple-negative breast cancer (TNBC). Cancer Chemother. Pharm. 2011, 68, 753-761. [CrossRef]

51. Byrski, T.; Dent, R.; Blecharz, P.; Foszczynska-Kloda, M.; Gronwald, J.; Huzarski, T.; Cybulski, C.; Marczyk, E.; Chrzan, R.; Eisen, A.; et al. Results of a phase II open-label, non-randomized trial of cisplatin chemotherapy in patients with BRCA1-positive metastatic breast cancer. Breast Cancer Res. BCR 2012, 14, R110. [CrossRef] [PubMed]

52. Perez-Valles, A.; Martorell-Cebollada, M.; Nogueira-Vazquez, E.; Garcia-Garcia, J.A.; Fuster-Diana, E. The usefulness of antibodies to the BRCA1 protein in detecting the mutated BRCA1 gene. An immunohistochemical study. J. Clin. Pathol. 2001, 54, 476-480. [CrossRef] [PubMed]

53. Vorrius, T.R.; Snyder, K.; Pica-Mendez, A.; Tan, C.; Laterza, O.; Toniatti, C.; Carpenter, C.; Lee, H.; Tanaka, W.; Zhang, Z.-Q. Immunohistochemical Detection of BRCA-1 and BRCA-2 Expression in Human Breast and Ovarian Tumors. J. Histotechnol. 2009, 32, 202-203. [CrossRef]

54. Xu, C.F.; Chambers, J.A.; Solomon, E. Complex regulation of the BRCA1 gene. J. Biol. Chem. 1997, 272, 20994-20997. [CrossRef] [PubMed]

55. Rice, J.C.; Ozcelik, H.; Maxeiner, P.; Andrulis, I.; Futscher, B.W. Methylation of the BRCA1 promoter is associated with decreased BRCA1 mRNA levels in clinical breast cancer specimens. Carcinogenesis 2000, 21, 1761-1765. [CrossRef]

56. Bianco, T.; Chenevix-Trench, G.; Walsh, D.C.; Cooper, J.E.; Dobrovic, A. Tumour-specific distribution of BRCA1 promoter region methylation supports a pathogenetic role in breast and ovarian cancer. Carcinogenesis 2000, 21, 147-151. [CrossRef]

57. Kondrashova, O.; Topp, M.; Nesic, K.; Lieschke, E.; Ho, G.Y.; Harrell, M.I.; Zapparoli, G.V.; Hadley, A.; Holian, R.; Boehm, E.; et al. Methylation of all BRCA1 copies predicts response to the PARP inhibitor rucaparib in ovarian carcinoma. Nat. Commun. 2018, 9, 3970. [CrossRef]

58. Ignatov, T.; Poehlmann, A.; Ignatov, A.; Schinlauer, A.; Costa, S.D.; Roessner, A.; Kalinski, T.; Bischoff, J. BRCA1 promoter methylation is a marker of better response to anthracycline-based therapy in sporadic TNBC. Breast Cancer Res. Treat. 2013, 141, 205-212. [CrossRef]

59. Stefansson, O.A.; Villanueva, A.; Vidal, A.; Marti, L.; Esteller, M. BRCA1 epigenetic inactivation predicts sensitivity to platinum-based chemotherapy in breast and ovarian cancer. Epigenetics 2012, 7, 1225-1229. [CrossRef]

60. Xu, Y.; Diao, L.; Chen, Y.; Liu, Y.; Wang, C.; Ouyang, T.; Li, J.; Wang, T.; Fan, Z.; Fan, T.; et al. Promoter methylation of BRCA1 in triple-negative breast cancer predicts sensitivity to adjuvant chemotherapy. Ann. Oncol. Off. J. Eur. Soc. Med. Oncol. ESMO 2013, 24, 1498-1505. [CrossRef]

61. Tutt, A.; Tovey, H.; Cheang, M.C.U.; Kernaghan, S.; Kilburn, L.; Gazinska, P.; Owen, J.; Abraham, J.; Barrett, S.; Barrett-Lee, P.; et al. Carboplatin in BRCA1/2-mutated and triple-negative breast cancer BRCAness subgroups: The TNT Trial. Nat. Med. 2018, 24, 628-637. [CrossRef] [PubMed]

62. Baker, L.A.; Holliday, H.; Swarbrick, A. ID4 controls luminal lineage commitment in normal mammary epithelium and inhibits BRCA1 function in basal-like breast cancer. Endocr. Relat. Cancer 2016, 23, R381-R392. [CrossRef] [PubMed]

63. Crippa, E.; Lusa, L.; De Cecco, L.; Marchesi, E.; Calin, G.A.; Radice, P.; Manoukian, S.; Peissel, B.; Daidone, M.G.; Gariboldi, M.; et al. miR-342 regulates BRCA1 expression through modulation of ID4 in breast cancer. PLoS ONE 2014, 9, e87039. [CrossRef] [PubMed] 
64. Roldan, G.; Delgado, L.; Muse, I.M. Tumoral expression of BRCA1, estrogen receptor alpha and ID4 protein in patients with sporadic breast cancer. Cancer Biol. 2006, 5, 505-510. [CrossRef]

65. Thike, A.A.; Tan, P.H.; Ikeda, M.; Iqbal, J. Increased ID4 expression, accompanied by mutant p53 accumulation and loss of BRCA1/2 proteins in triple-negative breast cancer, adversely affects survival. Histopathology 2016, 68, 702-712. [CrossRef]

66. Wen, Y.H.; Ho, A.; Patil, S.; Akram, M.; Catalano, J.; Eaton, A.; Norton, L.; Benezra, R.; Brogi, E. Id4 protein is highly expressed in triple-negative breast carcinomas: Possible implications for BRCA1 downregulation. Breast Cancer Res. Treat. 2012, 135, 93-102. [CrossRef]

67. Garcia, A.I.; Buisson, M.; Bertrand, P.; Rimokh, R.; Rouleau, E.; Lopez, B.S.; Lidereau, R.; Mikaelian, I.; Mazoyer, S. Down-regulation of BRCA1 expression by miR-146a and miR-146b-5p in triple negative sporadic breast cancers. EMBO Mol. Med. 2011, 3, 279-290. [CrossRef]

68. Matamala, N.; Vargas, M.T.; Gonzalez-Campora, R.; Arias, J.I.; Menendez, P.; Andres-Leon, E.; Yanowsky, K.; Llaneza-Folgueras, A.; Minambres, R.; Martinez-Delgado, B.; et al. MicroRNA deregulation in triple negative breast cancer reveals a role of miR-498 in regulating BRCA1 expression. Oncotarget 2016, 7, 20068-20079. [CrossRef]

69. Tan, X.; Peng, J.; Fu, Y.; An, S.; Rezaei, K.; Tabbara, S.; Teal, C.B.; Man, Y.G.; Brem, R.F.; Fu, S.W. miR-638 mediated regulation of BRCA1 affects DNA repair and sensitivity to UV and cisplatin in triple-negative breast cancer. Breast Cancer Res. BCR 2014, 16, 435. [CrossRef]

70. Boukerroucha, M.; Josse, C.; ElGuendi, S.; Boujemla, B.; Freres, P.; Maree, R.; Wenric, S.; Segers, K.; Collignon, J.; Jerusalem, G.; et al. Evaluation of BRCA1-related molecular features and microRNAs as prognostic factors for triple negative breast cancers. BMC Cancer 2015, 15, 755. [CrossRef]

71. Sobral-Leite, M.; Van de Vijver, K.; Michaut, M.; van der Linden, R.; Hooijer, G.K.J.; Horlings, H.M.; Severson, T.M.; Mulligan, A.M.; Weerasooriya, N.; Sanders, J.; et al. Assessment of PD-L1 expression across breast cancer molecular subtypes, in relation to mutation rate, BRCA1-like status, tumor-infiltrating immune cells and survival. Oncoimmunology 2018, 7, e1509820. [CrossRef] [PubMed]

72. Zhu, X.; Zhao, L.; Lang, J. The BRCA1 Methylation and PD-L1 Expression in Sporadic Ovarian Cancer. Int. J. Gynecol. Cancer 2018, 28, 1514-1519. [CrossRef] [PubMed]

73. Lamy, P.J.; Fina, F.; Bascoul-Mollevi, C.; Laberenne, A.C.; Martin, P.M.; Ouafik, L.; Jacot, W. Quantification and clinical relevance of gene amplification at chromosome 17q12-q21 in human epidermal growth factor receptor 2-amplified breast cancers. Breast Cancer Res. BCR 2011, 13, R15. [CrossRef] [PubMed]

74. Lamy, P.J.; Nanni, I.; Fina, F.; Bibeau, F.; Romain, S.; Dussert, C.; Penault Llorca, F.; Grenier, J.; Ouafik, L.H.; Martin, P.M. Reliability and discriminant validity of HER2 gene quantification and chromosome 17 aneusomy analysis by real-time PCR in primary breast cancer. Int. J. Biol. Markers 2006, 21, 20-29. [CrossRef]

75. Goldhirsch, A.; Glick, J.H.; Gelber, R.D.; Coates, A.S.; Thurlimann, B.; Senn, H.J. Meeting highlights: International expert consensus on the primary therapy of early breast cancer 2005. Ann. Oncol. Off. J. Eur. Soc. Med. Oncol. ESMO 2005, 16, 1569-1583. [CrossRef]

76. Jacot, W.; Gutowski, M.; Azria, D.; Romieu, G. Adjuvant early breast cancer systemic therapies according to daily used technologies. Crit. Rev. Oncol. Hematol. 2011. [CrossRef]

77. Guiu, S.; Mollevi, C.; Charon-Barra, C.; Boissiere, F.; Crapez, E.; Chartron, E.; Lamy, P.J.; Gutowski, M.; Bourgier, C.; Romieu, G.; et al. Prognostic value of androgen receptor and FOXA1 co-expression in non-metastatic triple negative breast cancer and correlation with other biomarkers. Br. J. Cancer 2018, 119, 76-79. [CrossRef]

(C) 2020 by the authors. Licensee MDPI, Basel, Switzerland. This article is an open access article distributed under the terms and conditions of the Creative Commons Attribution (CC BY) license (http://creativecommons.org/licenses/by/4.0/). 